\title{
In vivo antitumor and antimetastatic effects of flavokawain B in 4TI breast cancer cell-challenged mice
}

This article was published in the following Dove Press journal:

Drug Design, Development and Therapy

6 March 2015

Number of times this article has been viewed

\author{
Nadiah Abu ${ }^{1,2}$ \\ Nurul Elyani Mohamed ${ }^{2}$ \\ Swee Keong Yeap ${ }^{3}$ \\ Kian Lam Lim ${ }^{4}$ \\ M Nadeem Akhtar ${ }^{5}$ \\ Aimi Jamil Zulfadli ${ }^{3}$ \\ Beh Boon $\mathrm{Kee}^{2}$ \\ Mohd Puad Abdullah ${ }^{2}$ \\ Abdul Rahman Omar ${ }^{3}$ \\ Noorjahan Banu Alitheen ${ }^{2}$ \\ 'Bright Sparks Unit, Universiti Malaya, \\ Kuala Lumpur, Malaysia; ${ }^{2}$ Department \\ of Cell and Molecular Biology, Faculty \\ of Biotechnology and Biomolecular \\ Sciences, ${ }^{3}$ Institute of Bioscience, \\ Universiti Putra Malaysia, Serdang, \\ Selangor Darul Ehsan, Malaysia; \\ ${ }^{4}$ Faculty of Medicine and Health \\ Sciences, Universiti Tunku Abdul \\ Rahman, Lot PT, Jalan Sungai Long, \\ Bandar Sungai Long, Cheras, Selangor, \\ Malaysia; ${ }^{5}$ Faculty of Industrial \\ Sciences and Technology, Universiti \\ Malaysia Pahang, Lebuhraya Tun Razak, \\ Kuantan Pahang, Malaysia
}

Correspondence: Noorjahan Banu Alitheen

Department of Cell and Molecular Biology, Faculty of Biotechnology and Biomolecular Sciences, 43400, Universiti Putra Malaysia, Serdang, Selangor, Malaysia

Tel +6038946747 I

Fax +60389467510

Email noorjahan@upm.edu.my

\begin{abstract}
Flavokawain B (FKB) is a naturally occurring chalcone that can be isolated through the root extracts of the kava-kava plant (Piper methysticum). It can also be synthesized chemically to increase the yield. This compound is a promising candidate as a biological agent, as it is reported to be involved in a wide range of biological activities. Furthermore, FKB was reported to have antitumorigenic effects in several cancer cell lines in vitro. However, the in vivo antitumor effects of FKB have not been reported on yet. Breast cancer is one of the major causes of cancer-related deaths in the world today. Any potential treatment should not only impede the growth of the tumor, but also modulate the immune system efficiently and inhibit the formation of secondary tumors. As presented in our study, FKB induced apoptosis in 4T1 tumors in vivo, as evidenced by the terminal deoxynucleotidyl transferase dUTP nick end labeling and hematoxylin and eosin staining of the tumor. FKB also regulated the immune system by increasing both helper and cytolytic T-cell and natural killer cell populations. In addition, FKB also enhanced the levels of interleukin 2 and interferon gamma but suppressed interleukin 1B. Apart from that, FKB was also found to inhibit metastasis, as evaluated by clonogenic assay, bone marrow smearing assay, real-time polymerase chain reaction, Western blot, and proteome profiler analysis. All in all, FKB may serve as a promising anticancer agent, especially in treating breast cancer.
\end{abstract}

Keywords: flavokawain B, kava-kava, 4T1, cancer, metastasis

\section{Introduction}

The fight against cancer has been an ongoing battle. Cancer is still a major threat to human life. Among all the cancers diagnosed, breast cancer is one of the major causes of cancer-related deaths. ${ }^{1}$ Around one in eight women will develop breast cancer at some point in their lives. ${ }^{1}$ The search for a viable cure is still ongoing, and many findings have shown some promising progress. There are numerous natural bioactive substances that have been found to have anticancer potential. These anticancer agents can not only cease the growth of the tumor, but also increase the sensitivity of the immune system toward intruders. ${ }^{2}$ The performance of immune surveillance should be enhanced, especially in a cancer-promoting environment. ${ }^{2}$ Furthermore, the need to find anticancer agents that inhibit the metastatic process is also urgent. Metastasis is the number one reason cancer can lead to fatality. ${ }^{3}$ Therefore, it is imperative that newly discovered anticancer agents stop the progression of cancer as well as maintain an efficient immune system and impede the metastatic process.

Chalcones are a precursor of flavonoids and are known to be involved in a wide spectrum of biological activities. ${ }^{4}$ The kava-kava plant (Piper methysticum) is 
known as the Pacific elixir among Pacific islanders. ${ }^{5}$ There are three types of chalcones that can be extracted from the roots of this plant: flavokawain A, flavokawain B (FKB), and flavokawain $C .{ }^{6}$ These chalcones differ in terms of the side chain present within the molecular structure and the percentage of yield. FKB is a noteworthy chalcone that can either be isolated from the kava-kava plant or synthesized via the reaction of $4^{\prime}, 6^{\prime}$-dimethoxy-2'-hydroxyacetophenon and benzaldehyde. This compound is known to have promising anti-inflammatory, antinociceptive, and antitumorigenic properties. ${ }^{7}$ It also has been reported that FKB is toxic toward several bladder cancer cell lines, osteosarcoma cell lines, and synovial sarcoma cell lines. ${ }^{8-10}$ Nevertheless, the effects of FKB in a breast cancer murine model have not yet been tested. The extended effects of FKB on the immune system markers and metastatic markers also still remain elusive. Therefore, the purpose of this study was to unveil the in vivo antitumor effects of FKB against breast cancer in a murine model as well as to further understand the mechanism of action on immunity and antimetastasis activity.

\section{Materials and methods Preparation of FKB}

FKB was synthesized via the Claisen-Schmidt reaction, as performed by Mohamad et al. ${ }^{11}$ Mohamad et al also reported the purity of FKB. ${ }^{11}$ For the in vitro assays, FKB was dissolved in dimethylsulfoxide, with the volume of dimethylsulfoxide administered to the cells being less than $0.1 \%$.

\section{Cell culture}

4T1 cells were obtained from the American Type Culture Collection (ATCC, Manassas, VA, USA) and were maintained in RPMI-1640 supplemented with 10\% fetal bovine serum and $1 \%$ penicillin-streptomycin. All the cells were kept in a $37^{\circ} \mathrm{C}$ incubator equipped with $5 \% \mathrm{CO}_{2}$.

\section{MTT analysis}

Cell viability was measured through the MTT assay, as presented by Mosmann. ${ }^{12}$ Cells were seeded at a density of $0.8 \times 10^{5}$ cells $/ \mathrm{mL}$ in a 96 -well plate overnight. The following day, treatment with FKB was performed, starting with $30 \mu \mathrm{g} / \mathrm{mL}$ and followed by twofold serial dilutions. After 72 hours of treatment, $20 \mu \mathrm{L}$ MTT solution $(5 \mathrm{mg} / \mathrm{mL})$ was added to each of the wells. After 4 hours of incubation, the solution was removed and $100 \mu \mathrm{L}$ DMSO was added. The solubilized crystals were measured at $570 \mathrm{~nm}$, using the $\mu$ quant enzyme-linked immunosorbent assay plate reader (Bio-Tek Instruments, Winooska, VT, USA).

\section{Cell cycle analysis}

The cell cycle analysis was performed by flow cytometric experimentation. The cells were seeded at a density of $2.4 \times 10^{5}$ cells $/ \mathrm{mL}$ in 6 -well plates. The following day, the cells were treated with the desired treatments: $9 \mu \mathrm{g} / \mathrm{mL}$, $13.5 \mu \mathrm{g} / \mathrm{mL}$, and $28 \mu \mathrm{g} / \mathrm{mL}$ FKB for 24 hours. After the designated incubation time, the cells were harvested and fixed in $80 \%$ ethanol. The fixed pellets were kept in $-20^{\circ} \mathrm{C}$ for 1 week. On the day of the analysis, the cells were treated with Triton X-100 and RNAse and were stained with propidium iodide. Afterward, the cells were subjected to flow cytometric analysis, using the FACSCalibur System ${ }^{\mathrm{TM}}$ (BD, USA).

\section{Wound healing analysis}

The wound healing analysis was performed using 6-well plates according to Liang et al. ${ }^{13}$ The cells were grown to full confluence overnight in a $37^{\circ} \mathrm{C}$ incubator. The following day, a wound was introduced in the middle of the well, using a sterile yellow tip. Next, the medium was changed and the desired treatments $(9 \mu \mathrm{g} / \mathrm{mL}, 13.5 \mu \mathrm{g} / \mathrm{mL}$, and $28 \mu \mathrm{g} / \mathrm{mL}$ FKB) were added. Photographs of the wound were captured at 0 and 24 hours after treatment. The percentage of wound closure was calculated as follows: Percentage of wound closure $=($ area of wound at 0 hour - area wound at (n) hour $) /$ area of wound at 0 hour $\times 100$.

\section{In vitro migration/invasion assay}

The Boyden chamber assay was conducted to assess the rate of migration/invasion of 4T1 cells when presented with FKB. This assay was done according to Chen with minimal modification. ${ }^{14}$ Twenty-four hours before the assay, 4T1 cells were serum-starved by incubating the cells in serum-free media and kept in a $37^{\circ} \mathrm{C}$ and $5 \% \mathrm{CO}_{2}$ incubator. The next day, $650 \mu \mathrm{L}$ diluted matrigel (BD, USA) was coated on top of an $8 \mu \mathrm{m}$ transwell insert for the invasion assay, whereas for the migration assay, the membrane was left uncoated. The matrigel was left to solidify for 1 hour in $37^{\circ} \mathrm{C}$. Afterward, the cells were seeded on top of the transwell insert at $5 \times 10^{5}$ cells $/ \mathrm{mL}$ in serum-free media to create a chemoattractant gradient. For the bottom part of the insert, $2 \mathrm{~mL}$ media supplemented with $10 \%$ fetal bovine serum and the designated amounts of FKB were added. The cells were left to invade/migrate for 18 hours in a $37^{\circ} \mathrm{C} \mathrm{CO}_{2}$ incubator. After the incubation period, the cells on the bottom part of the inserts were fixed in methanol and were subsequently stained with $0.5 \%$ crystal 
violet. The number of invaded/migrated cells was viewed under an inverted light microscope (Nikon, Japan). The calculation for this assay was done by counting at least five fields of four sets from random sites of the transwell.

\section{Animal and diet}

Five- to 6-week-old female BALB/c mice were obtained from the Animal House of Monash University, Subang Jaya (Monash University, Malaysia). The mice were kept under standard housing conditions with a regular 12-hour darklight cycle at $25^{\circ} \mathrm{C} \pm 2{ }^{\circ} \mathrm{C}$. The mice were fed with standard diet pellets and clean tap water. All of the experiments using animals were conducted under the regulations set by the Universiti Putra Malaysia ethics committee's guidelines for the care of laboratory animals.

\section{Tumor inoculation and treatment}

All the mice were inoculated with $1 \times 10^{5} 4 \mathrm{~T} 1$ cells subcutaneously. The mice were separated into seven mice per group: normal, untreated, and FKB. The FKB treatment group was fed with $50 \mathrm{mg} / \mathrm{kg}$ per day of FKB orally, whereas the untreated group was fed with olive oil, which was the vehicle of delivery. This dose was selected on the basis of a study using a similar compound. ${ }^{15}$ After 28 days of treatment, the mice were anesthetized and then killed by cervical dislocation. The tumors were excised and kept in RNAlater, the organs (lung, liver, and spleen) were harvested and processed immediately, and the serum was collected for further analysis.

\section{Terminal deoxynucleotidyl transferase dUTP nick end labeling analysis of the tumors}

The terminal deoxynucleotidyl transferase dUTP nick end labeling (TUNEL) assay was conducted using the DeadEnd ${ }^{\mathrm{TM}}$ colorimetric TUNEL assay (Promega, USA), according to the user's guide. First, paraffin was removed from the slides in xylene for 5 minutes; this step was repeated twice. Next, the tissue sections were rehydrated in decreasing concentrations of ethanol $(100 \%, 95 \%, 85 \%, 70 \%$, and $50 \%)$ before being washed in phosphate-buffered serum (PBS; pH 7.0). Then the slides were fixed in $4 \%$ paraformaldehyde and permeabilized using proteinase $\mathrm{K}$ for 30 minutes. Next, the slides were equilibrated using the provided equilibration buffer, and then the slides were labeled using terminal deoxynucleotidyl transferase. Afterward, the slides were blocked in hydrogen peroxide before being incubated with streptavidin horseradish peroxidase (HRP). Last, the slides were developed using 3,3' diaminobenzidine and were mounted in glycerol. The slides were viewed under a bright-field inverted microscope, and the apoptotic cells were counted in at least five fields of the slides from random sections of the tumors (Nikon, Japan).

\section{Hematoxylin and eosin histology staining of the tumors}

The harvested tumors were fixed in $10 \%$ formalin and were embedded in paraffin before being sliced into thin sections. Then the paraffin sections were stained with hematoxylin and eosin (H\&E) and were viewed under a bright-field microscope (Nikon, Japan). The mitotic cells present were counted and compared between the groups. The slides were viewed under a bright-field inverted microscope, and the mitotic cells were counted in at least five fields of the slides from random sections of the tumors (Nikon, Japan).

\section{Nitric oxide detection in tumors}

To detect the level of nitric oxide, the Griess reagent Kit (Sigma, USA) was used per the user's manual. The samples were mixed with the Griess reagent and deionized water, and the mixture was left to incubate for 30 minutes at room temperature. Afterward, the absorbance of the mixture was measured at $548 \mathrm{~nm}$, using a spectrophotometer (Beckmon Coulter, USA).

\section{Serum detection of interleukin 2 , interferon $\gamma$, and interleukin I $\beta$}

The levels of these cytokines; interleukin 2 (IL-2), interferon $\gamma$ (IFN- $\gamma$ ), IL-10, and IL-1 $\beta$ were detected using enzyme-linked immunosorbent assay kits (R\&D Systems, USA). Basically, 96-well plates were coated with the designated capture antibodies and were left overnight in $4^{\circ} \mathrm{C}$. The following day, the plates were washed three times with PBS-0.5\% Tween 20. Next, serums obtained from mice were incubated in the 96-well plates for 2 hours on a rocking platform at room temperature. Afterward, the plates were washed for three times again. Then the plates were incubated with the detection antibody for 2 hours on a rocking platform at room temperature. Once the incubation time ended, the plates were repeatedly washed three times and then incubated in streptavidin-HRP for 30 minutes. Next, the plates were washed four times and the $3,3^{\prime}, 5,5^{\prime}$-tetramethylbenzidine substrate was loaded into the plates. Once the color developed, $100 \mu \mathrm{L}$ stop solution was added and the plates were read using the $\mu$ Quant ${ }^{\mathrm{TM}}$ microplate reader (Bio-Tek Instruments).

\section{Immunophenotyping of splenocytes}

The spleens harvested from the mice from each group were meshed with a $70 \mu \mathrm{m}$ strainer, and the single-cell suspensions 
were washed twice with ice-cold PBS. Next, red blood cells were removed by incubating the splenocytes in lysis buffer ( $8 \mathrm{~g} \mathrm{NH}_{4} \mathrm{Cl}, 1 \mathrm{~g} \mathrm{Na}_{2}$ EDTA, $0.1 \mathrm{~g} \mathrm{KH}_{2} \mathrm{PO}_{4}$ at $\mathrm{pH}$ 7.4) for 15 minutes at $4^{\circ} \mathrm{C}$. After that, the cells were washed again with PBS twice before being stained with the appropriate antibodies (Abcam, USA) for 2 hours. Later, the cells were washed with PBS and were fixed in 4\% paraformaldehyde. A week later, the stained cells were run through the FACSCalibur flow cytometry system (BD, USA).

\section{Lung, liver, and spleen clonogenic assay}

The clonogenic assay was based on DuPré et al's protocol. ${ }^{16}$ The lungs, livers, and spleens were harvested from each group of the mice and were rinsed several times in ice-cold PBS. Next, the liver and lung were chopped and minced into small pieces before being treated with $2 \mathrm{mg} / \mathrm{mL}$ collagenase type IV in $37^{\circ} \mathrm{C}$ for 1 hour. Afterward, the digested organs were passed through a $70 \mu \mathrm{m}$ strainer. The spleens were mechanically disrupted using a syringe plunger and $70 \mu \mathrm{m}$ strainers. The digested organs were centrifuged at 2,000 rpm for 5 minutes. Later, the cell pellets were washed with PBS twice before being resuspended in $10 \mathrm{~mL}$ RPMI supplemented with $10 \%$ fetal bovine serum and $60 \mu \mathrm{M}$ 6-thioguanine (Fisher, USA). The whole-organ suspension was plated into 6-well plates, and tenfold serial dilutions were made. The plates were incubated in a $37^{\circ} \mathrm{C}$ incubator equipped with $5 \% \mathrm{CO}_{2}$ for 10 days with no media change. After the incubation period, the unattached cells were removed and the plates washed with PBS. The colonies were fixed in methanol for 1 hour and stained with $0.5 \%$ crystal violet for 2 hours. The wells were rinsed with PBS again and viewed under a microscope. The number of colonies formed per organ was counted for each group.

\section{Bone marrow smearing}

The bone marrows from the mice were removed from the femur of the mice, using dissecting scalpel and scissors. Afterward, the bone marrows were flushed with PBS, using a syringe. Then, the cells from the bone marrow were smeared across a clean slide and were left to dry. Afterward, the slides were fixed in methanol for 30 minutes and later stained with Giemsa staining for 1 hour before being rinsed in distilled $\mathrm{H}_{2} 0$ three times. The slides were left to dry, and the morphology of the cells was observed under an inverted microscope (Nikon, Japan).

\section{Total red blood cell count}

Total red blood cell count was performed using a standard hemocytometer. The blood from mice was withdrawn and inserted into a microtainer. Ten microliters of the blood were loaded onto the hemocytometer and counted. The total count was done under a standard light microscope (Nikon, Japan).

\section{Real-time quantitative polymerase chain reaction}

Total RNA was extracted from the tumors using the Qiagen RNEASY Mini Kit (Qiagen, Germany). Then, $1 \mu \mathrm{g}$ of the RNA was converted to cDNA, using the First Strand Maxima Synthesis Kit (Thermo Scientific, USA) on a thermal cycler (Labnet, USA). Next, the real-time polymerase chain reaction was conducted using the Power SybrGreen Kit (Invitrogen, USA) on the iCyler IQ5 (Bio-Rad, USA). The sequence of the primers used is detailed in Table 1. The analysis was done using the iQ5 icycler software, using three housekeeping genes: HPRT, ACTB, and GAPDH.

Table I Accession number, name of the gene, and the sequence of the primers used in the real-time polymerase chain reaction analysis

\begin{tabular}{lll}
\hline Accession number & Gene & Sequence \\
\hline NM_008084.3 & GAPDH & F: 5-GAAGGTGGTGAAGCAGGCATC-3 \\
NM_007393.3 & ACTB 5 -GAAGGTGGAAGAGTGGGAGTT-3 & F: 5-TTCCAGCCTTCCTTCTTG-3 \\
NM_013556.2 & R: 5-GGAGCCAGAGCAGTAATC-3 \\
NM_010493.2 & HPRT & F: 5-CGTGATTAGCGATGATGAAC-3 \\
& Intercellular adhesion molecule I & R-AATGTAATCCAGCAGGTCAG-3 \\
NM_010927.3 & & F: 5-TGCTCAGGTATCCATCCATCC-3 \\
NM_008689.2 & Inducible nitric oxide synthase & R: 5-ACGGTGCCACAGTTCTCAA-3 \\
NM_010849.4 & & F: 5-GCACCGAGATTVGGAGTTC-3 \\
& Nuclear factor $k B$ & R: 5-GAGCACAGCCACATTGAT-3 \\
& & F: 5-CATTCTGACCTTGCCTATCT-3 \\
& C-MYC & R: 5-CTGCTGTTCTGTCCATTCT-3 \\
& & F: 5-TGATGTGGTGTCTGTGGAGAA-3 \\
& & R: 5-CGTAGTTGTGCTGGTGAGTG-3 \\
\hline
\end{tabular}




\section{Western blot}

Proteins from the tumor excised from the mice were obtained by mechanical disintegration, using radioimmunoprecipitation assay buffer supplemented with protease inhibitors (Roche, USA). The quantification of the proteins was performed using the Bradford assay (Sigma, USA). Next, $100 \mu \mathrm{g}$ protein run on a $10 \%$ sodium dodecyl sulfate polyacrylamide gel electrophoresis gel before the protein separated was transferred onto a nitrocellulose membrane using the G2 Pierce Blotter (Pierce, USA). Afterward, the membrane was blocked with $0.5 \%$ skimmed milk overnight, and the membrane was washed in Tris-buffered saline with Tween 20 three times. Next, the membrane was incubated in the respective primary antibodies for 1 hour, followed by a 1 hour incubation with the secondary antibodies. The anti-beta-actin loading control antibody (ab8227; Abcam, USA) was incubated at a 1:2,000 ratio, and the antivascular endothelial growth factor (VEGF; ab1316; Abcam, USA) antibody was incubated at a 1:1,000 ratio. The membrane was then developed under chemiluminescence conditions and was viewed using the ChemiDoc XRS (Bio-Rad).

\section{Proteome profiler mouse angiogenesis}

To analyze the effects of FKB on the angiogenic process in $4 \mathrm{~T} 1$ tumors, a proteome profiler analysis was performed (R\&D Systems, USA). In short, proteins from the excised tumors were harvested via mechanical disruption, during which the tumors were snapped in liquid nitrogen and meshed using a mortar and pestle. The meshed tumors were lysed in PBS supplemented with premade tablets containing protease cocktail inhibitors (Roche, USA). The quantification of the proteins was done using the Bradford assay (Sigma, USA). Initially, the membranes were blocked in the blocking buffer provided for 1 hour at room temperature. At the same time, the proteins also were incubated with the detection antibody for 1 hour at room temperature. After the blocking period, the samples and detection antibody were incubated with the membrane at $4{ }^{\circ} \mathrm{C}$ overnight. The following day, the membranes were washed three times with the provided washing buffer. Next, a 1:2,000 dilution of the streptavidin-HRP was prepared and was incubated alongside the membranes for 30 minutes. Afterward, the membranes were washed again three times before being developed under chemiluminescence conditions. The membrane was viewed using the ChemiDoc XRS (Bio-Rad).

\section{Statistical analysis}

All experiments were done in at least four biological replicates. The average values and standard errors of the mean were obtained. The statistical analysis was performed using the GraphPad Prism (version 4.0), based on Student's $t$-tests with the significance set at $P<0.05$ against the untreated group.

\section{Results \\ FKB inhibits the proliferation and induces apoptosis of 4TI cells in vitro}

To screen whether FKB is cytotoxic toward 4T1 cells or not, the MTT assay was conducted before any other assays. As depicted in Figure 1, FKB managed to inhibit the growth of $4 \mathrm{~T} 1$ cells in a dose-dependent manner. The half-maximal dose of FKB was $13.5 \mu \mathrm{g} / \mathrm{mL}$ after 72 hours of treatment. Furthermore, to analyze the effect of FKB on the cell cycle regulation of $4 \mathrm{~T} 1$ cells, the flow cytometric analysis was performed as in Figure 2. As depicted in Table 2, the percentage of the cells in the SubG0/G1 phase increased as the dose of FKB escalated.

\section{FKB impedes the migration and invasion of $4 \mathrm{TI}$ cells in vitro}

To determine the effects of FKB on the in vitro motility and invasiveness of $4 \mathrm{~T} 1$ cells, three assays were conducted. As depicted in Figure 3A, the wound healing analysis was performed to observe whether FKB impeded the migration of the $4 \mathrm{~T} 1$ cells toward the center of the wound. After 24 hours of incubation, the percentage of wound closure decreased substantially in the treated samples. The percentage of wound closures declined from $100 \%$ to $54.26 \% \pm 6.14 \%$ in the $9 \mu \mathrm{g} / \mathrm{mL}$ treatment group, $43.6 \% \pm 2.41 \%$ in the $13.5 \mu \mathrm{g} / \mathrm{mL}$ treatment group, and $33.72 \% \pm 2.78 \%$ in the $28 \mu \mathrm{g} / \mathrm{mL}$ treatment group. To observe the effects of FKB on the migration of 4T1 cells in a three-dimensional setting, the Boyden transwell chamber assay was performed. As depicted in Figure 3B, the percentage

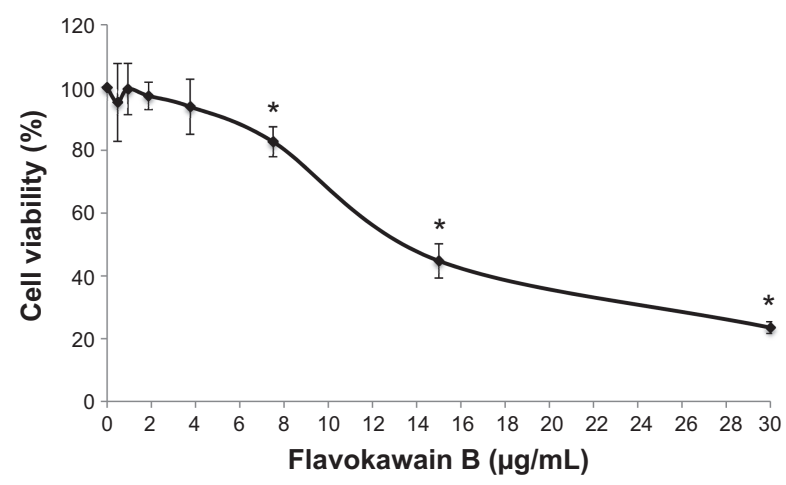

Figure I MTT analysis on 4T I cells after treatment with seven different concentrations of flavokawain B for 72 hours.

Notes: All values are represented as mean \pm standard error of the mean; $n=3$ biological replicates of $4 \mathrm{TI}$ cells. $* P<0.05$. 


\section{Control}

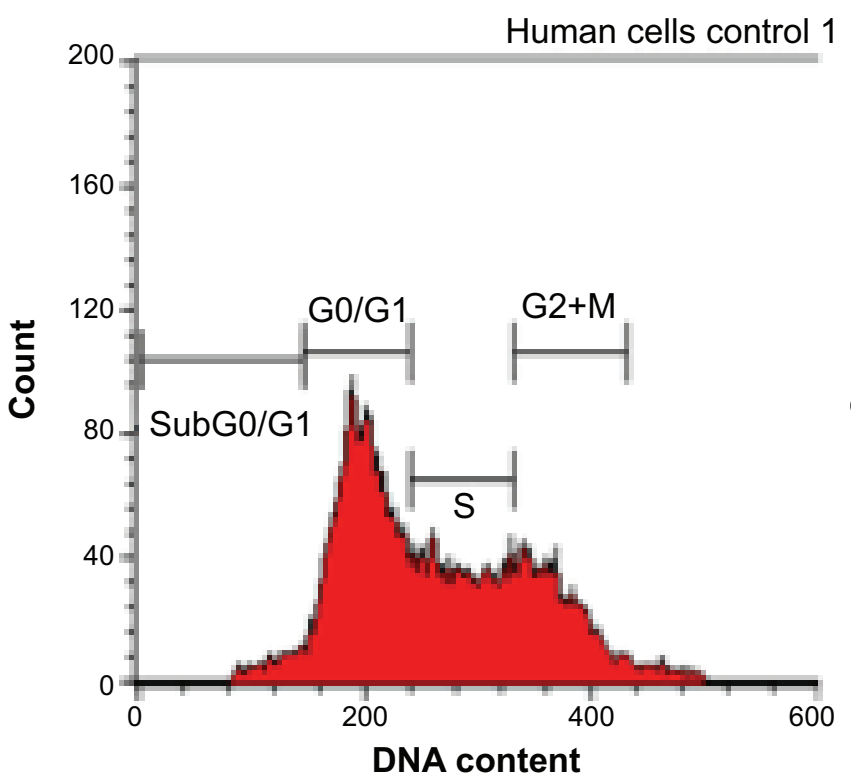

$13.5 \mu \mathrm{g} / \mathrm{mL}$

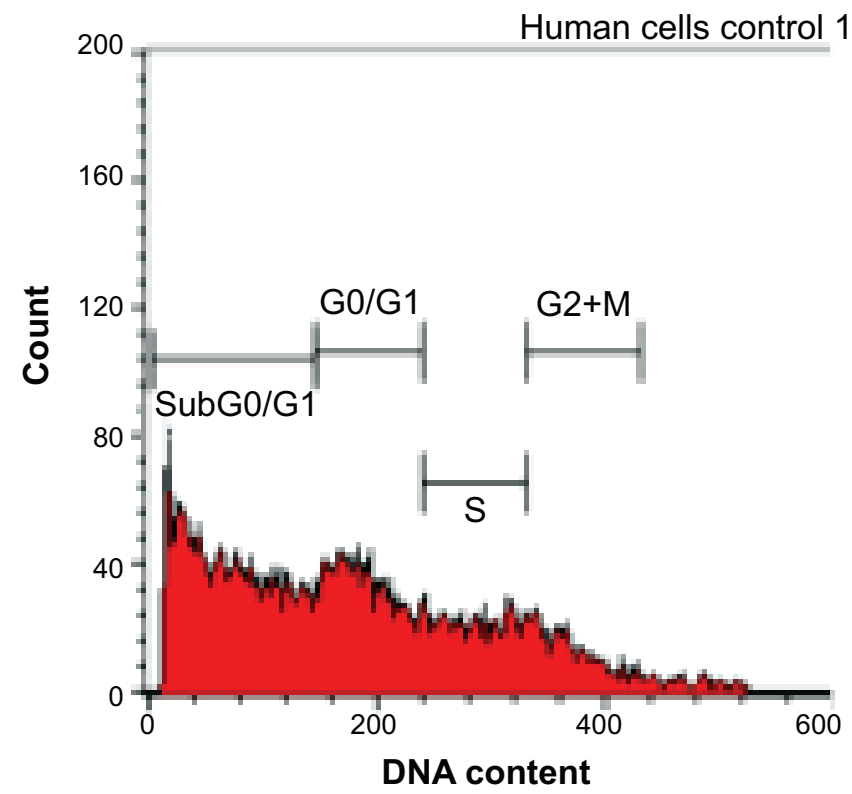

$9 \mu \mathrm{g} / \mathrm{mL}$

Human cells control 1

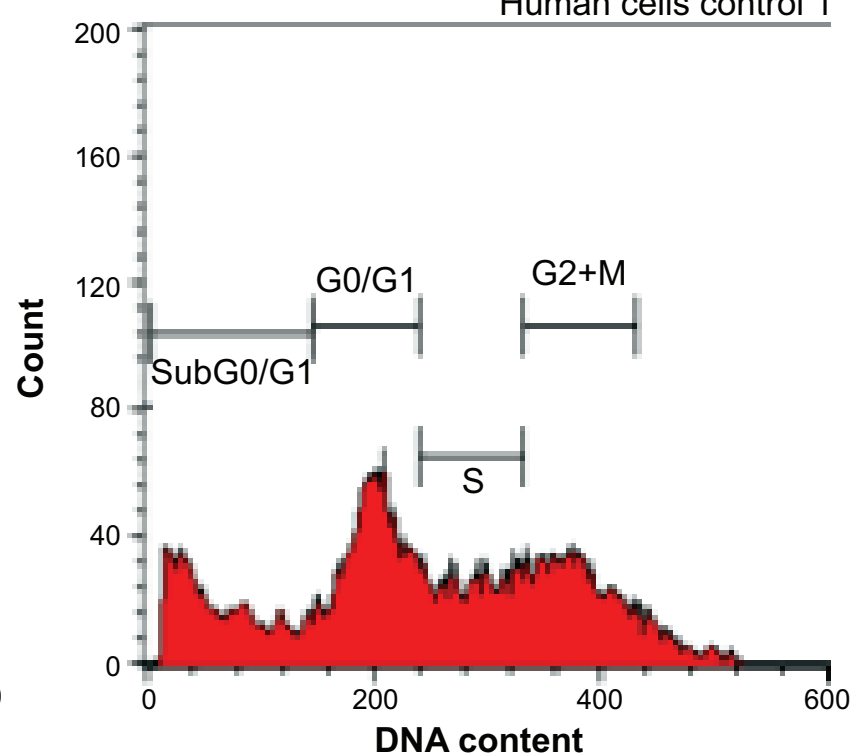

$28 \mu \mathrm{g} / \mathrm{mL}$

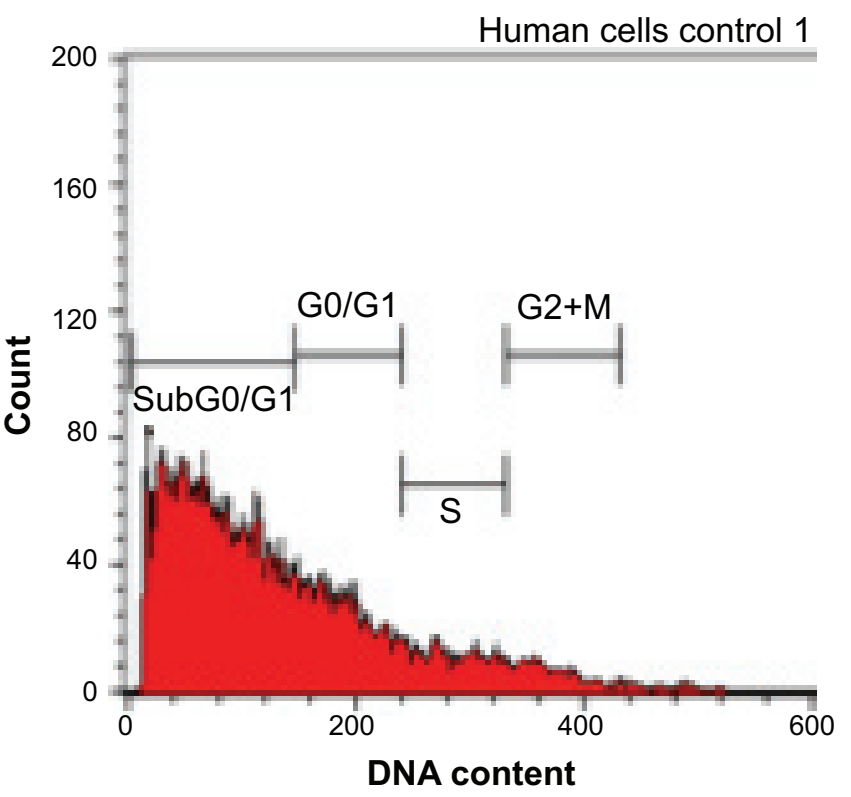

Figure 2 Cell cycle analysis of 4TI cells after treatment with three different concentrations of flavokawain B for 72 hours. Notes: $n=3$ biological replicates of $4 \mathrm{TI}$ cells.

Table 2 Percentage of cells in each of the cell cycle phases after treatment with flavokawain B for 72 hours

\begin{tabular}{lllll}
\hline & Control & $9 \mu \mathrm{g} / \mathrm{mL}$ & $13.5 \mu \mathrm{g} / \mathrm{mL}$ & $\mathbf{2 8} \mu \mathrm{g} / \mathrm{mL}$ \\
\hline Sub G0/GI & $2.53 \pm 0.17$ & $20.1 \mathrm{I} \pm 0.4 I^{*}$ & $45.73 \pm 0.4 I^{*}$ & $64.96 \pm 0.36^{*}$ \\
G0/GI & $46.67 \pm 0.35$ & $31.27 \pm 0.53$ & $27.25 \pm 0.72^{*}$ & $22.29 \pm 0.33^{*}$ \\
S & $28.64 \pm 0.32$ & $20.95 \pm 0.23$ & $16.17 \pm 0.25$ & $8.31 \pm 0.19 *$ \\
G2+M & $20.67 \pm 0.21$ & $23.96 \pm 0.38$ & $9.67 \pm 0.34^{*}$ & $4.05 \pm 0.12^{*}$ \\
\hline
\end{tabular}

Notes: Each value represents mean \pm standard error of the mean. $* P<0.05$. of migrated cells also decreased significantly in the treatment group. In terms of the invasiveness of 4T1 cells, the ability is reduced on treatment with FKB, as presented in Figure 3C.

FKB inhibits the growth of tumors in vivo FKB managed to reduce the size of the tumor after 28 days of treatment, as depicted in Figure 4A. Likewise, in Figure 4B, 


\section{A}

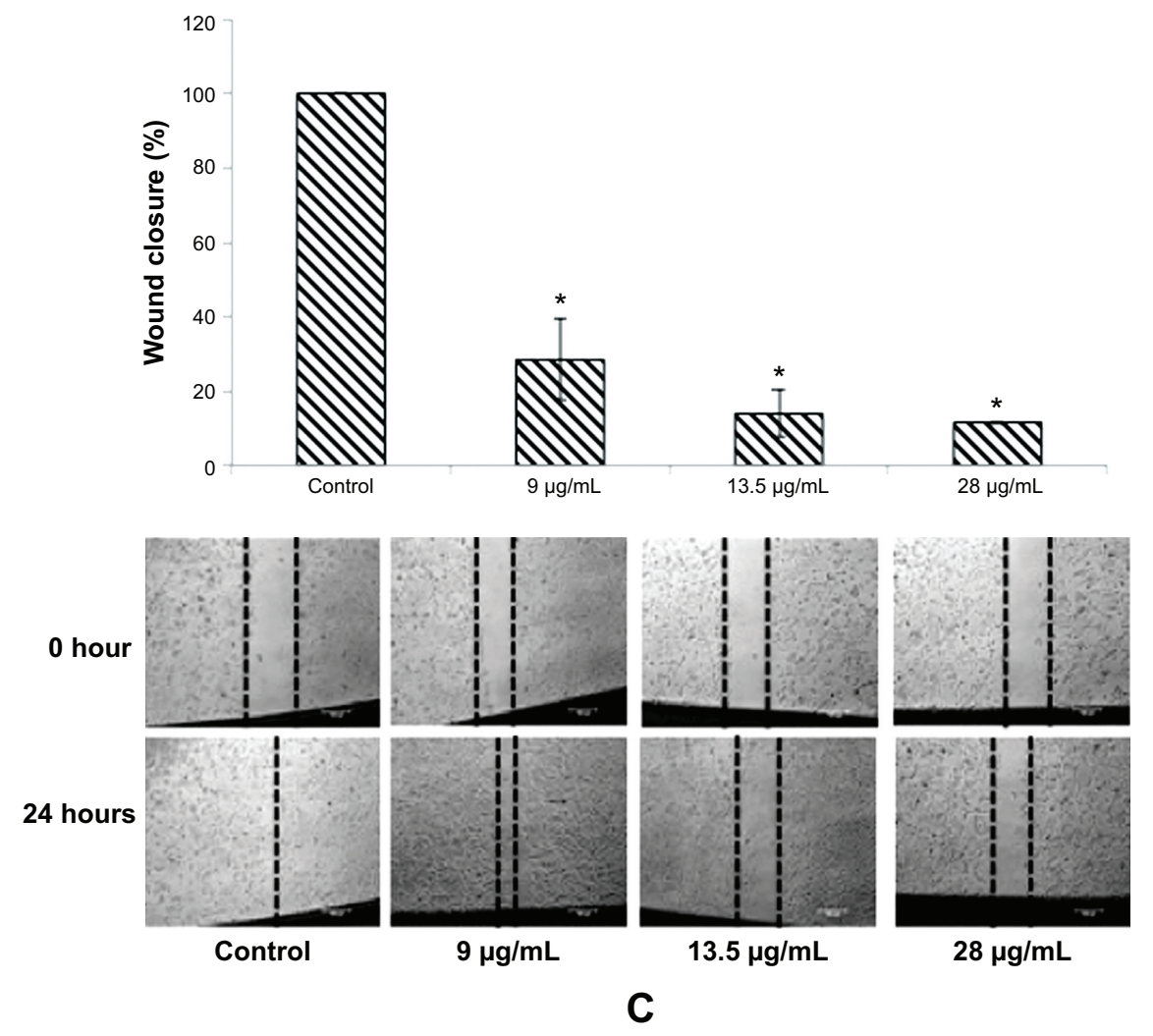

B
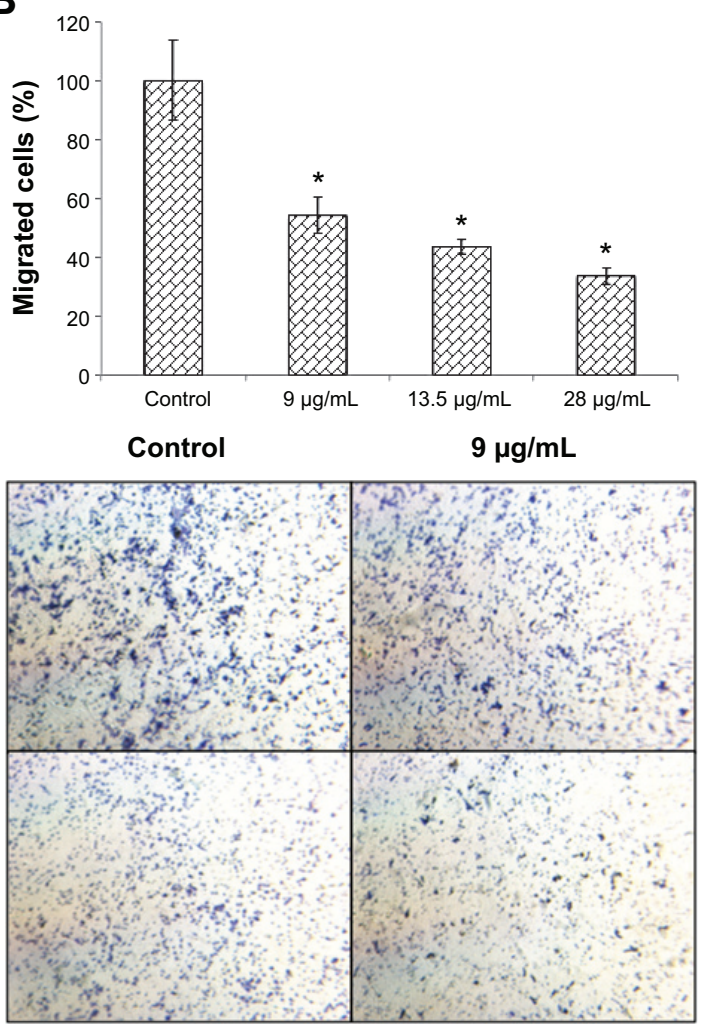

$13.5 \mu \mathrm{g} / \mathrm{mL}$

$28 \mu \mathrm{g} / \mathrm{mL}$

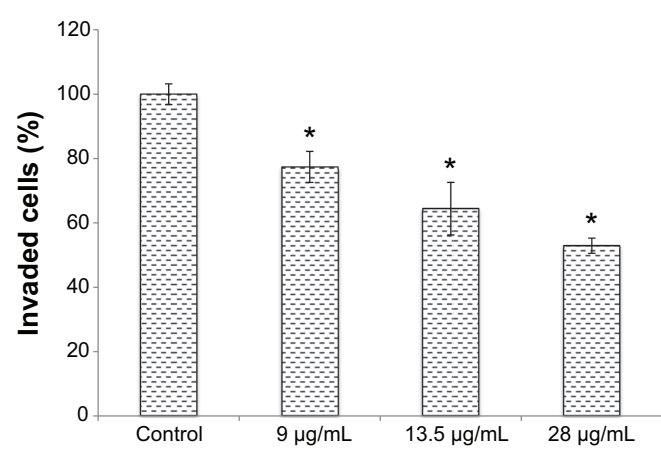

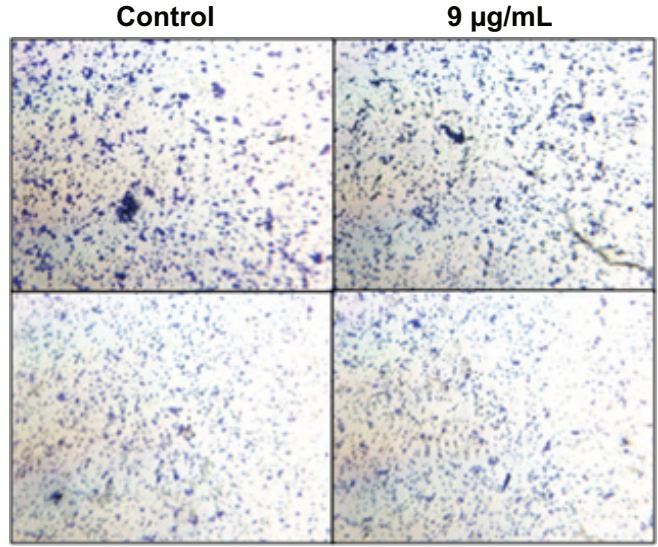

$13.5 \mu \mathrm{g} / \mathrm{mL}$

$28 \mu \mathrm{g} / \mathrm{mL}$

Figure 3 In vitro migration/invasion results in 4TI cells upon treatment with flavokawain B.

Notes: (A) Wound healing analysis of 4TI cells after treatment with three concentrations of flavokawain B for 24 hours. (B) Percentage of migrated cells in the in vitro migration assay of $4 \mathrm{TI}$ cells through a Boyden chamber alongside three different doses of flavokawain B for 18 hours. (C) Percentage of invaded cells in the in vitro invasion

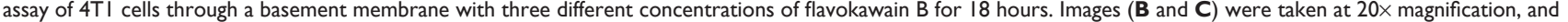
were stained with crystal violet. All values are represented as mean \pm standard error of the mean; significance was set at $P<0.05$. $* P<0.05$. 

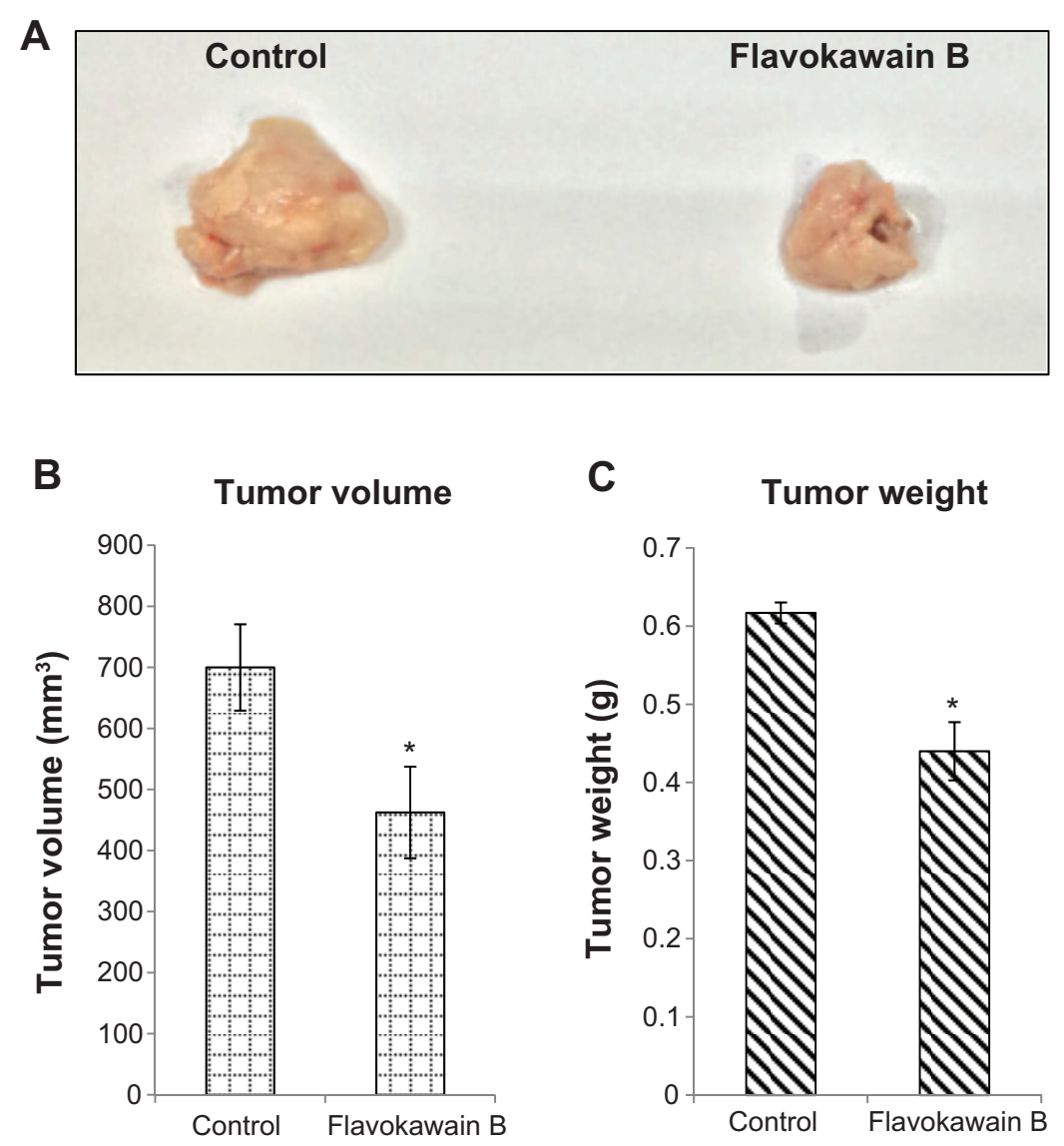

Figure 4 Tumor size and weight harvested from the control and flavokawain b-treated mice.

Notes: (A) Picture of the tumors harvested from the control and flavokawain B (50 mg/kg)-treated mice. (B) Volume of the tumors was measured using a vernier caliper. (C) Weight of the tumors was measured after being harvested from the mice after 28 days of treatment. Each value represents the mean \pm standard deviation for triplicates $(* P<0.05) ; n=7$ mice per group.

the tumor volume also decreased from $700 \pm 70 \mathrm{~mm}^{3}$ in the untreated group to $462.5 \pm 74 \mathrm{~mm}^{3}$ in the FKB-treated group. The weight of the tumor in the untreated group was $0.617 \pm 0.013 \mathrm{~g}$, whereas this value decreased to $0.44 \pm 0.037 \mathrm{~g}$ in the treatment group, as depicted in Figure 4C. Moreover, on the basis of the TUNEL analysis, the number of apoptotic cells in the tumors increased in the FKB-treated tumors, as in Figure 5. In addition, according to the H\&E staining, as illustrated in Figure 5, the number of mitotic cells decreased in the FKB-treated tumors.

\section{FKB regulates several immune system markers in vivo}

To understand the effects of FKB on the important immune markers, immunophenotyping of the splenocyte cell population was conducted. As depicted in Figure 6, the population of the CD4/CD3 T-cell population increased significantly in the FKB-treated splenocytes. A similar pattern was also observed in the population of CD8/CD4 T-cells. In addition, the population of both natural killer (NK) $1.1 / \mathrm{CD}^{+}$and
NK1.1/CD3- cells was elevated slightly, even though it is not statistically significant. To further elucidate the mechanistic action of FKB, the levels of expression of several important cytokines was also measured, as presented in Figure 7. The level of IL-2 in the serum of the control mice was 35.09士 $7.54 \mathrm{pg} / \mathrm{mL}$, whereas in the FKB group, the level of IL-2 increased to $141.11 \pm 1.22 \mathrm{pg} / \mathrm{mL}$. Moreover, as depicted in Figure 7, the level of IFN- $\gamma$ also increased from $94.21 \pm 1.91$ $\mathrm{pg} / \mathrm{mL}$ in the control group to $174.82 \pm 0.52 \mathrm{pg} / \mathrm{mL}$ in the FKB-treated serum. Moreover, on the basis of the level of IL-1 $\beta$, the value in the control group, $666.67 \pm 7.63 \mathrm{pg} / \mathrm{mL}$, decreased to $433.33 \pm 2.88 \mathrm{pg} / \mathrm{mL}$ in the FKB-treated mice. Moreover, as depicted in Table 3, the red blood count in FKB-treated mice increased compared with in the control.

\section{FKB possesses antimetastatic abilities in vivo}

To test for the antimetastatic potential of FKB in vivo, the clonogenic assay was performed. As depicted in Figure 8, the number of colonies formed in the lung, liver, and spleen was 

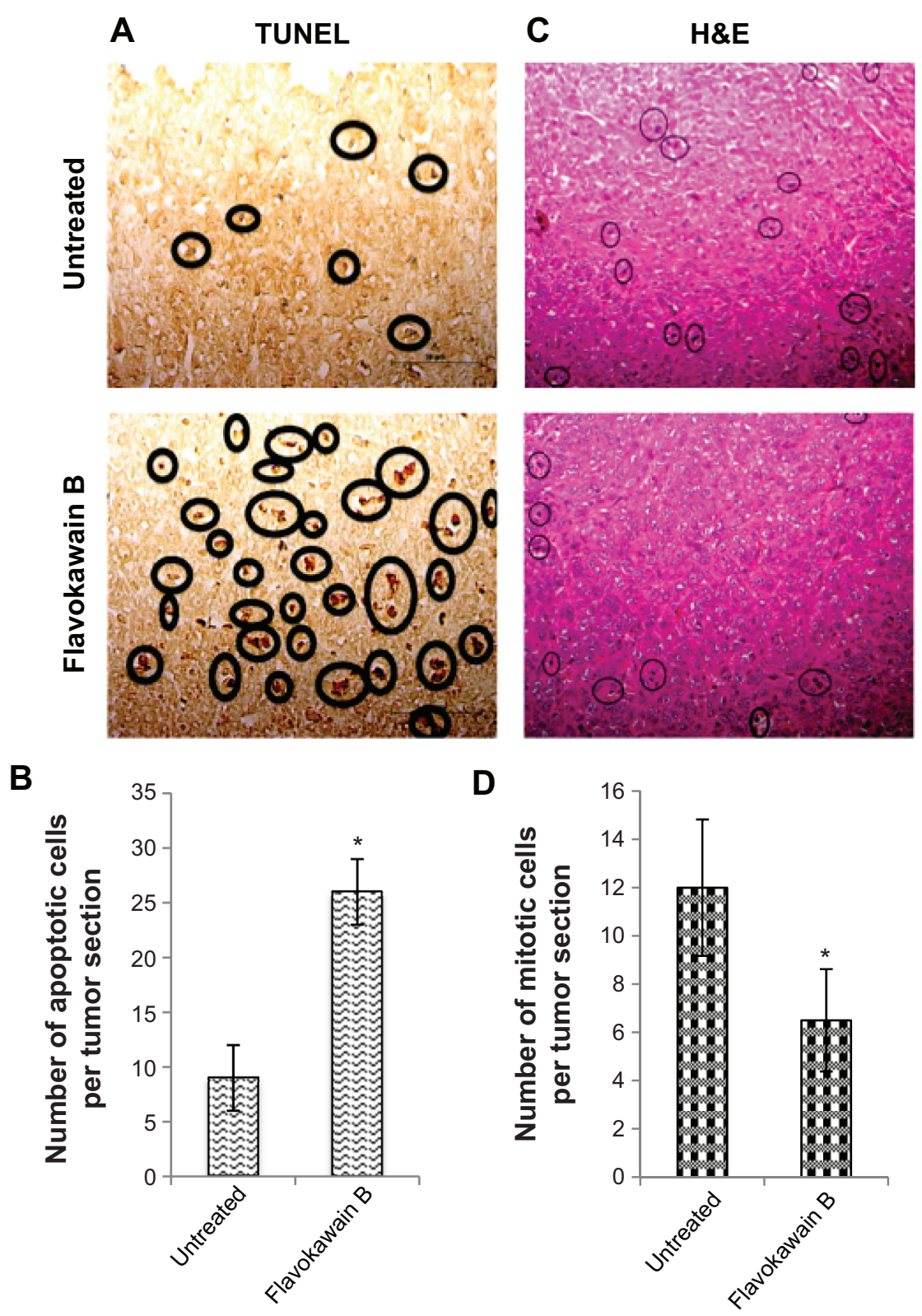

Figure 5 Terminal deoxynucleotidyl transferase dUTP nick end labeling (TUNEL) analysis of tumors harvested from both control mice as well as flavokawain B (50 mg/kg)treated mice (A), and quantified (B). Histological staining of both the tumors (control and flavokawain B-treated) with hematoxylin and eosin (H\&E) (C), and quantified (D). Notes: (A) Black circles represent cells with fragmented DNA (apoptotic cells). Magnification, 40x. (C) Circles represent cells undergoing mitoses. Magnification: 20x. *Significance is set at $P<0.05$, and each value represents mean \pm standard error of the mean; $n=7$ mice per group.

reduced significantly in the FKB treatment group. In addition, on the basis of the bone marrow smearing assay, as shown in Figure 9, the presence of abnormal cells was only seen in the untreated group, not in the FKB treatment group.

\section{FKB regulates inflammation and metastasis-related genes and proteins in vivo}

The level of nitric oxide in the tumors was also measured. As shown in Figure 10, the level of nitric oxide in FKB-treated tumors was reduced when compared with the control. Realtime polymerase chain reaction was conducted to measure the levels of messenger RNA of four different genes in the tumor lysates. As presented in Figure 11, the levels of nuclear factor $\mathrm{\kappa B}$, inducible nitric oxide synthase, intercellular adhesion molecule 1, and C-MYC declined in the FKB-treated mice. This pattern was also seen in the protein level of VEGF, as illustrated in Figure 12. Furthermore, on the basis of the proteome profiler analysis, the levels of several angiogenesisrelated proteins were also decreased in the FKB-treated group, 


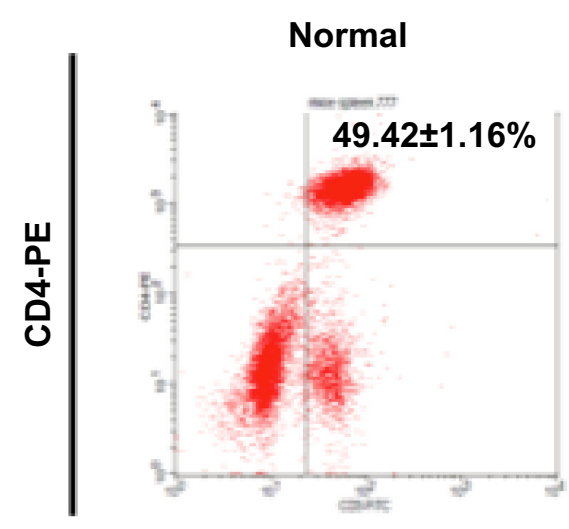

Untreated
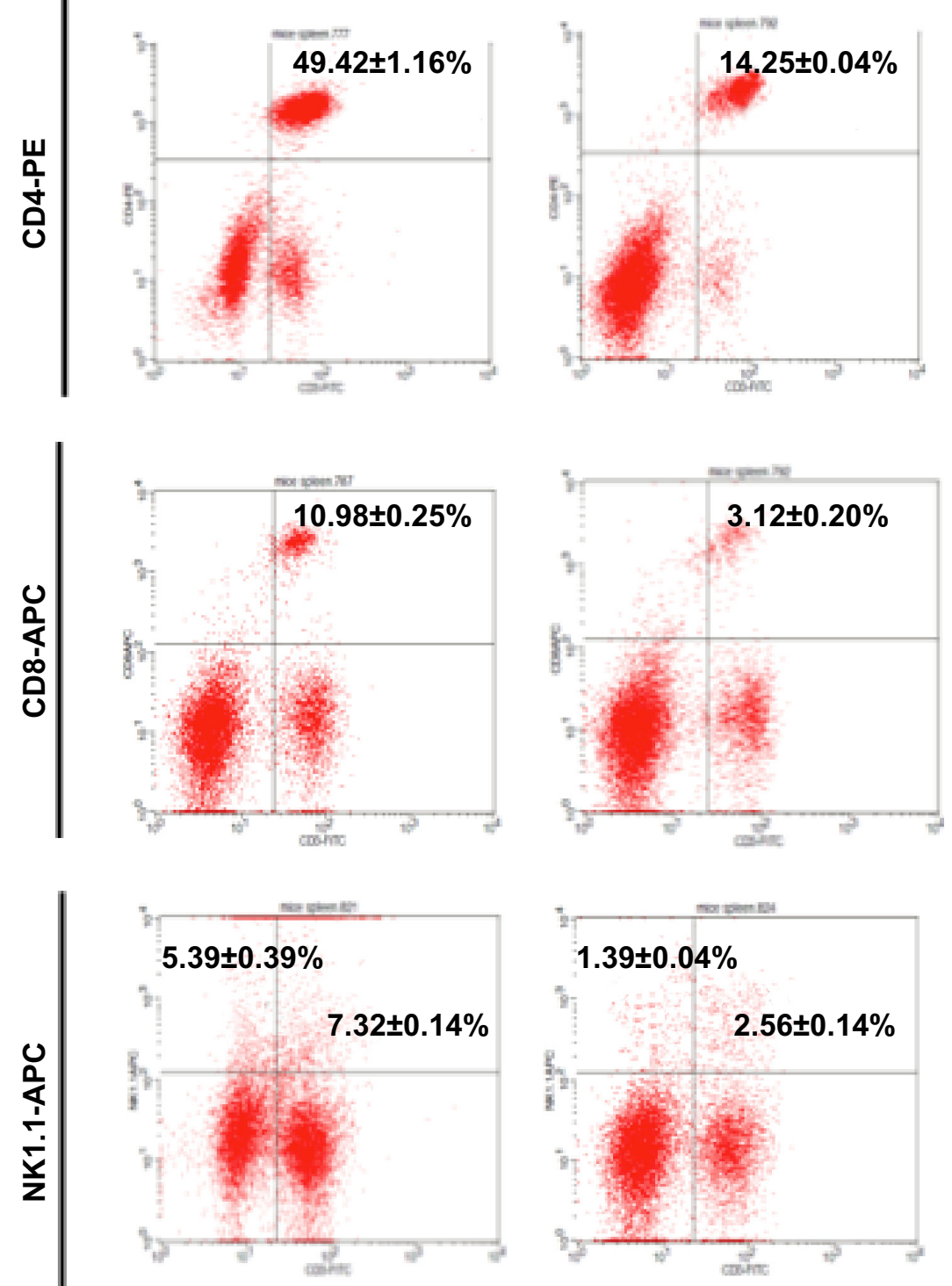

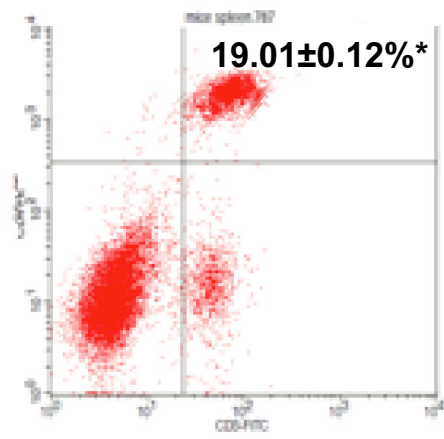

Flavokawain B
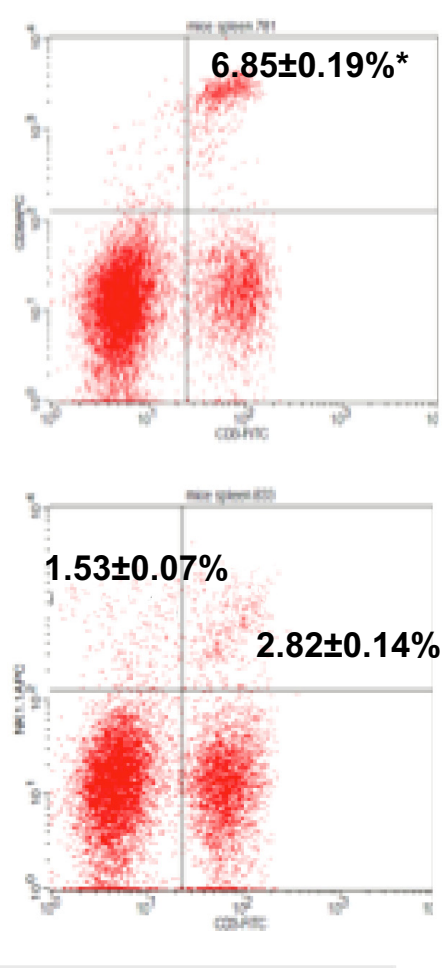

\section{CD3-FITC}

Figure 6 Flow cytometry analysis of four immune markers (CD3, CD4, CD8, and NKI.I) on the splenocytes of both the control and flavokawain B $(50 \mathrm{mg} / \mathrm{kg})$-treated mice.

Notes: Each value represents the mean \pm standard error of the mean for triplicates. Significance is set at $* p<0.05 ; n=7$ mice per group.

as shown in Figure 13. These proteins included angiogenin, TIMP-1, coagulation factor 3, SDF-1, serpin E1, FGF Acidic, FGF Basic, TSP-2, Endothelin 1, IP-10, KC, PDGF-AA, PDGF-BB, Pentraxin 3, IGFBP-1, and IGFBP-2.

\section{Discussion}

FKB has been found to possess promising antitumorigenic properties in several cancer cell lines in vitro. ${ }^{7-10}$ However, to the best of our knowledge, the effects of FKB on breast cancer cell line, 4T1 cells, in a murine model have not yet been reported. In the in vitro model, FKB inhibited the proliferation of 4T1 cells on the basis of the MTT assay and the cell cycle analysis. Moreover, the abilities of FKB to inhibit the migration and invasiveness of 4T1 cells were also discovered. Because the antitumorigenic properties of FKB in an in vitro setting are promising, this notion was put to test in an in vivo model. After 28 days of treatment, FKB managed to reduce the size in terms of weight and volume of 

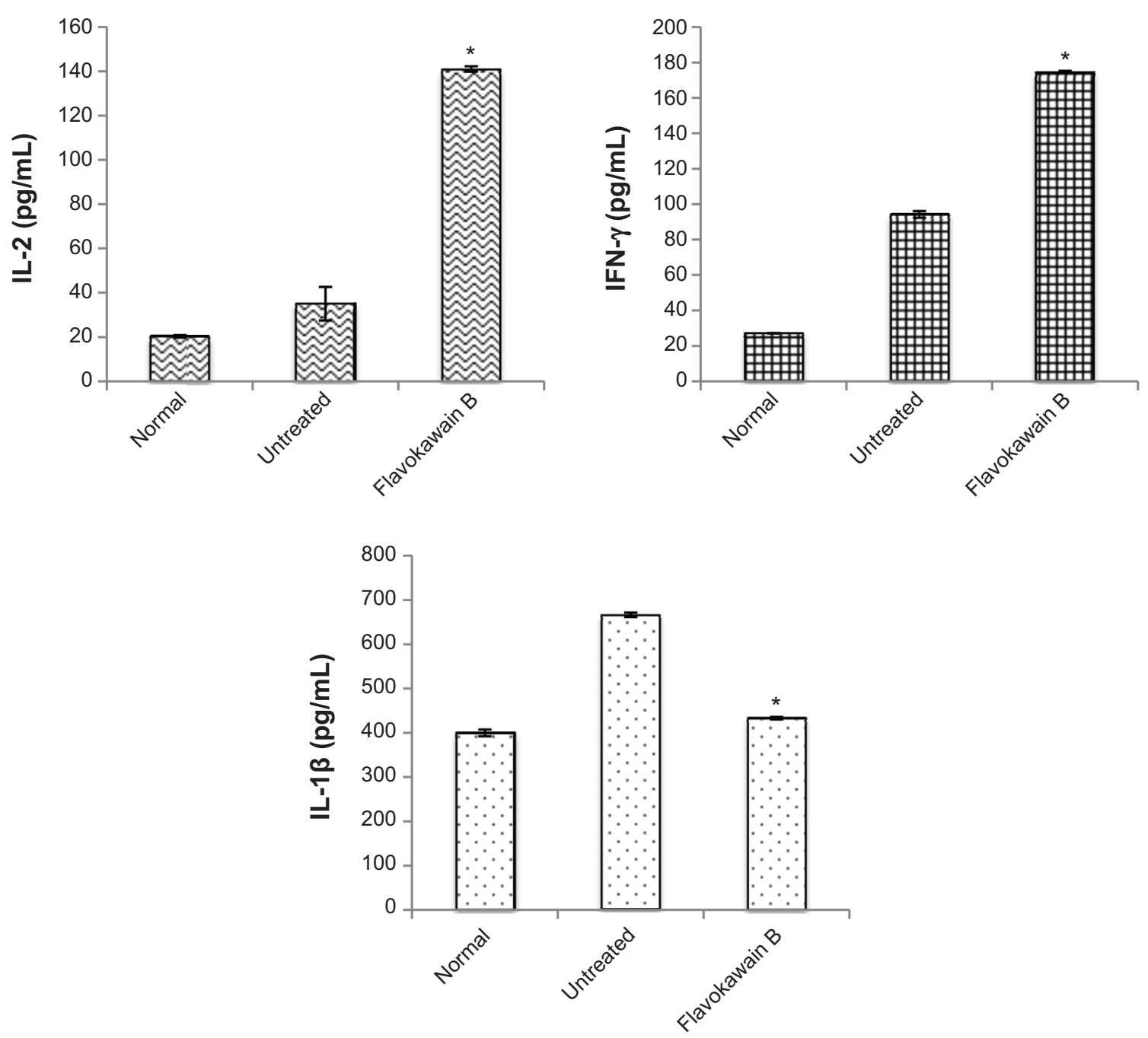

Figure 7 Enzyme-linked immunosorbent assay analysis on the detection of the level of interleukin 2 (IL-2), interferon $\gamma($ IFN- $\gamma$ ), and interleukin I $\beta$ (IL-I $\beta$ ) in the blood of the normal, untreated, and flavokawain B $(50 \mathrm{mg} / \mathrm{kg})$-treated mice.

Notes: Each value represents the mean \pm standard error of the mean; $n=7$ mice per group; $* P<0.05$.

the tumors. TUNEL analysis was performed to see whether FKB induced apoptosis in the tumors by DNA fragmentation. DNA fragmentation is an essential step in the execution of apoptosis. ${ }^{17}$ Furthermore, according to the H\&E staining of the tumors, the number of actively dividing cells in the FKBtreated tumors was reduced when compared with the untreated control tumor. Cancer cells are distinguishable because of the high rate of division in them. ${ }^{18} \mathrm{C}-\mathrm{MYC}$ is a proto-oncogene that is heavily involved in the progression of cancer. ${ }^{19,20} \mathrm{It}$ is

Table 3 Total red blood count in the serum harvested from the control and flavokawain B (50 mg/kg)-treated mice

\begin{tabular}{ll}
\hline Mice & Total red blood cell count, $10^{12} / \mathrm{L}$ \\
\hline Control & 3.40 \\
Flavokawain B & 8.08 \\
\hline
\end{tabular}

linked to the poor prognosis of breast cancer and is known to promote cancer cell survival. ${ }^{21}$ The quantitative polymerase chain reaction analysis showed that the expression of c-MYC decreased significantly in the FKB-treated tumors. A similar flavonoid, fucoidan, also induced apoptosis in 4T1 cells by decreasing the level of C-MYC. ${ }^{22}$ According to these results, it could be suggested that FKB obstructed the progression of 4T1 tumors by inducing apoptosis.

The state of the immune system is thoroughly important to the progression of cancer. A compromised immune system may contribute to the aggressiveness of a certain cancer. Tumor cells are able to evade immune surveillance by interrupting the activity of T-cells. ${ }^{23} \mathrm{~T}$-cells provide a barrier that cancer cells have to overcome before rendering the host vulnerable and weak. ${ }^{24}$ In contrast, advances in using cytokines and T-cells as immunotherapy had been 


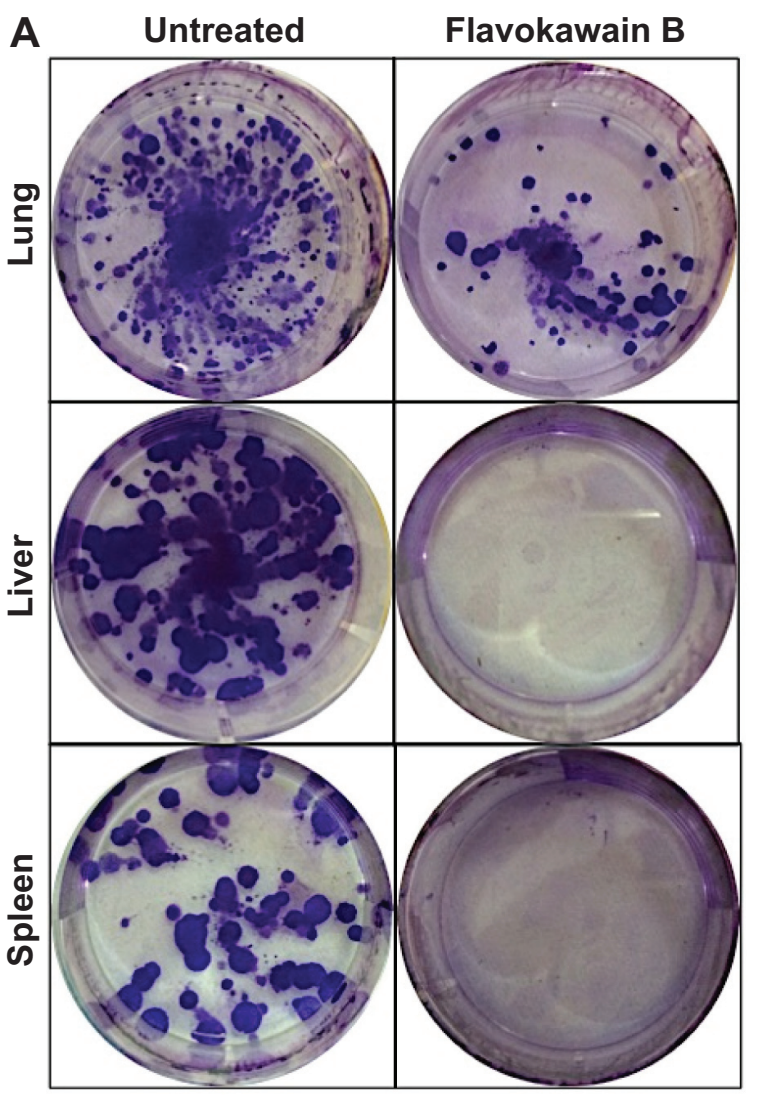

\section{B}

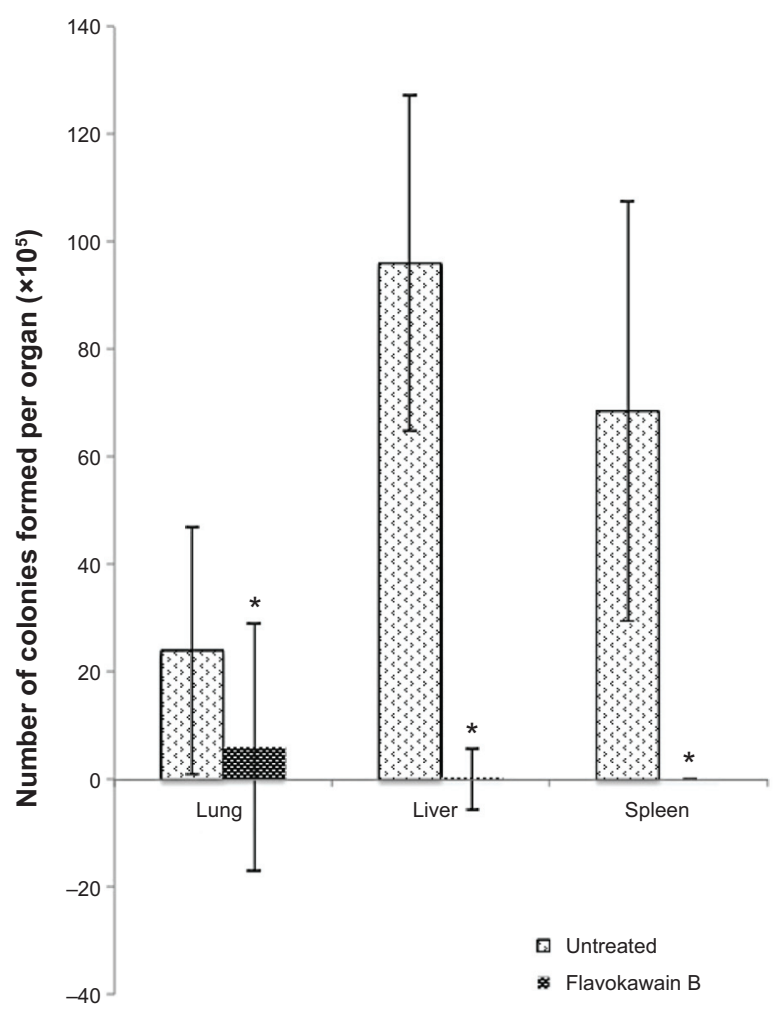

Figure 8 Representative images of the colonies formed in each of the organs (A). Bar chart of the total 4TI colonies formed from the meshed lung, liver, and spleen harvested from the control and flavokawain B $(50 \mathrm{mg} / \mathrm{kg})$-treated mice after 10 days of incubation (B).

Notes: (A) Lung, dilution factor: 104; liver, dilution factor: 104; spleen, dilution factor: $10^{5}$. (B) Each value represents mean \pm standard error of the mean; $* P<0.05$; $n=3$.

expanding rapidly. ${ }^{24,25}$ It is apparent that FKB increased the cell populations of several T-cell markers and the NK1.1 cell population. The percentages of CD8/CD3 T-cells and NK cells also increased in the FKB-treated splenocytes. Both cytotoxic T-cells and NK cells contribute to the elimination of cancer cells by lysing the tumors. ${ }^{23} \mathrm{CD} 4 / \mathrm{CD} 3 \mathrm{~T}$-cells are commonly referred to as $\mathrm{T}$ helper cells, and these cells are one of the main immune players in the body. These $\mathrm{T}$ helper

\section{Control}

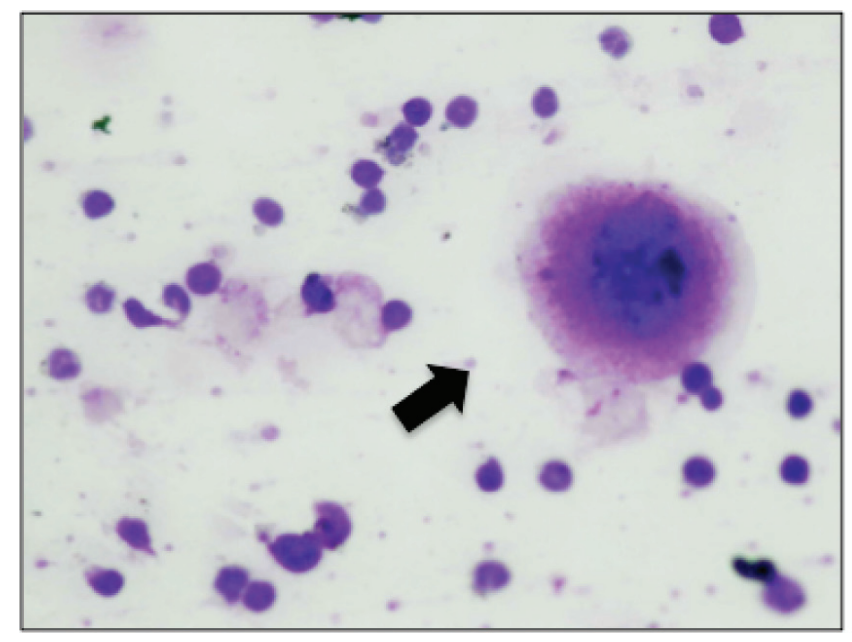

Flavokawain B

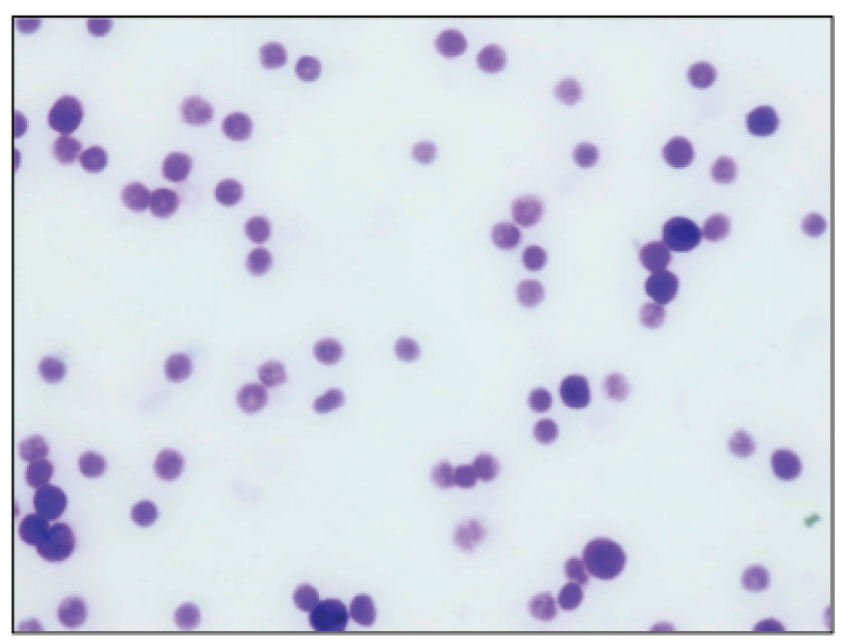

Figure 9 Bone marrow cells stained with Giemsa viewed under a phase contrast microscope.

Notes: Black arrow indicates the presence of abnormal cells within the cell population. Abnormal cells are identified by the morphology difference. Magnification: $40 \times$. 


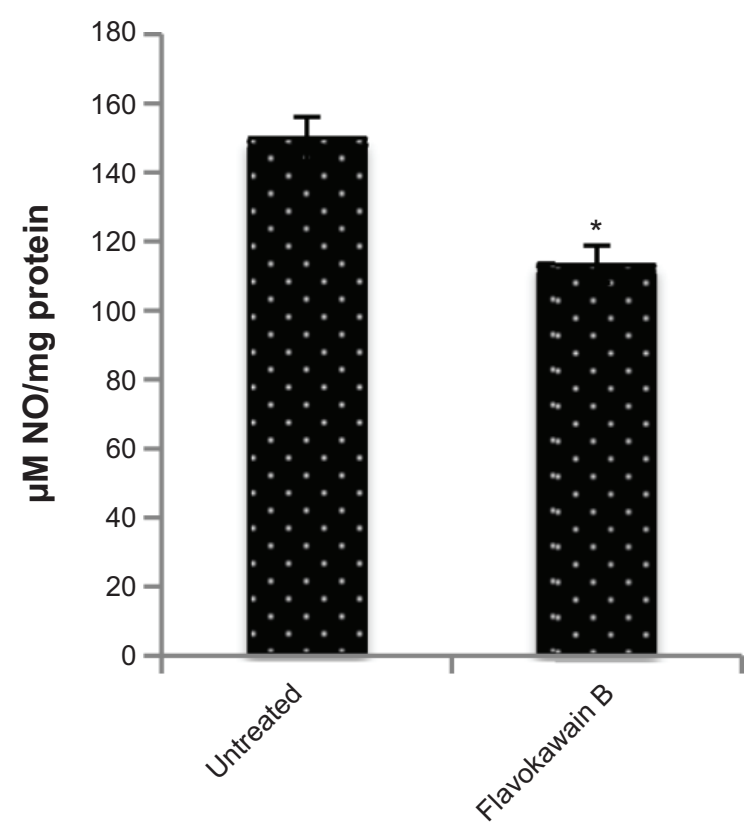

Figure 10 Level of nitric oxide in the tumors harvested from the control group and flavokawain B (50 mg/kg/day) group.

Notes: Each value represents the mean \pm standard deviation; $n=7$ mice per group; $* P<0.05$.

cells function by maintaining the effectiveness of CD8 cells as well as generating memory T-cells for future use. ${ }^{26} \mathrm{NK}$ $\mathrm{T}$-cells are also a recognized subset of T-cells that has the potential to have therapeutic values in suppressing cancer.

On another related note, cytokines also play crucial roles in regulating the immune system. IL-2 is necessary for T-cells to develop into T helper cells and T cytotoxic cells. ${ }^{27}$ Therefore, the increase in the levels of IL-2 may assist in the productivity of T-cell activity, thus enhancing the immune system. Furthermore, the level of IFN- $\gamma$ also increased in the FKB-treated mice. Interestingly, IL-2 is associated with

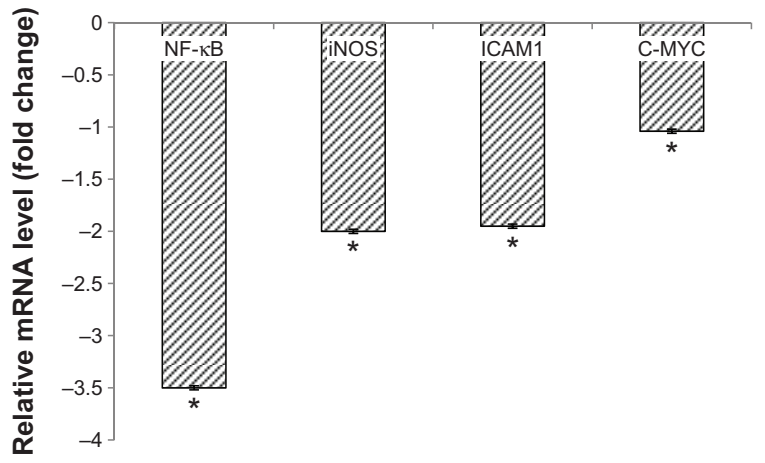

Figure I I Quantitative polymerase chain reaction analysis was done to detect the messenger RNA (mRNA) levels of nuclear factor (NF)- $\kappa B$, inducible nitric oxide synthase (iNOS), intercellular adhesion molecule I (ICAMI), and C-MYC in the tumors of the control and flavokawain B $(50 \mathrm{mg} / \mathrm{kg} /$ day $)$-treated mice.

Notes: Each value represents the mean \pm standard deviation for triplicates; $* P<0.05$.

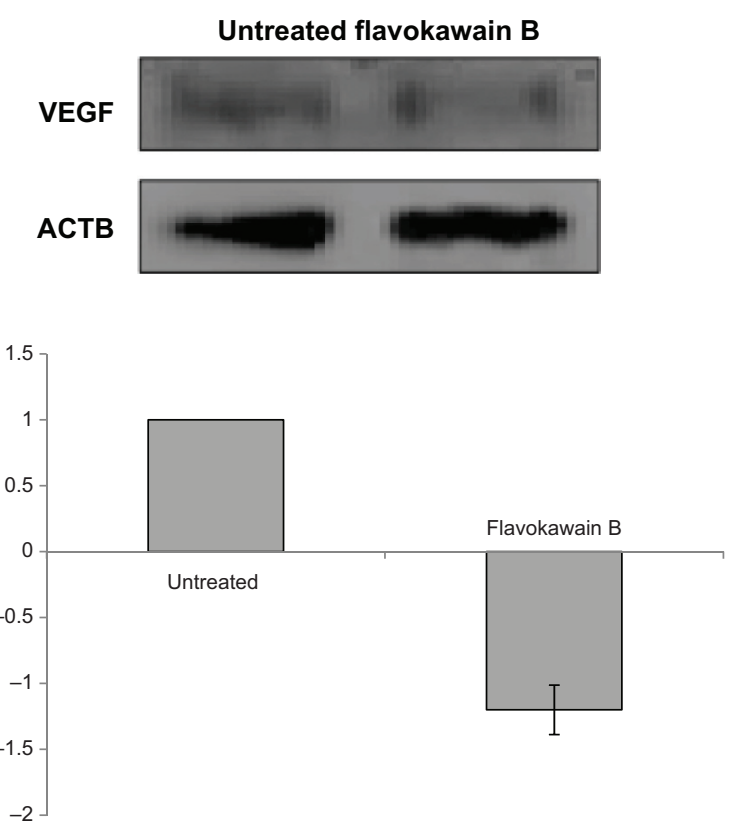

Figure 12 Western blot analysis vascular endothelial growth factor (VEGF) in the tumor lysates harvested from both control and flavokawain B $(50 \mathrm{mg} / \mathrm{kg} / \mathrm{day})$ treated mice.

Note: ACTB (beta-actin) serves as a loading control.

the activation of the IFN- $\gamma$-induced chemokine signaling pathway that will eventually regulate the CD8/CD3 T-cells. ${ }^{28}$ Thus, the activation of the cytolytic CD8 T-cells and NK cells with the stimulation of anticancer cytokines (IL-2 and IFN- $\gamma$ ) may also contribute to the inhibition of cancer. Cancer treatment usually causes unwanted adverse effects, including low red blood cell count. Red blood cells are important to maintain the optimum oxygen delivery to other tissues. The increase in the red blood cell count may suggest that FKB does not interfere with bone marrow activities. IL- $1 \beta$ is a type of cytokine known to be involved in the progression of cancer. ${ }^{29}$ In fact, the inhibition of this cytokine may impede tumor growth and, to a greater extent, metastasis in general. ${ }^{29}$

The positive relationship between inflammation and progression of cancer, especially metastasis, is a popular doctrine. ${ }^{30}$ An inflammatory response might interfere with the efficacy of the immune markers. The level of nitric oxide within the tumor is reduced on treatment with FKB. Nitric oxide may contribute to the development of inflammation, metastasis, and angiogenesis. ${ }^{31}$ The generation of $\mathrm{NO}$ is a result of the activation of nuclear factor $\kappa B$ and, subsequently, inducible nitric oxide synthase. ${ }^{32}$ Nuclear factor $\kappa B$ can also directly regulate the level of intercellular adhesion molecule 1, a proinflammatory marker that is reduced in the FKB treatment group. ${ }^{33}$ Most of the cancer-related fatalities were reported to be caused by the formation of secondary 
A

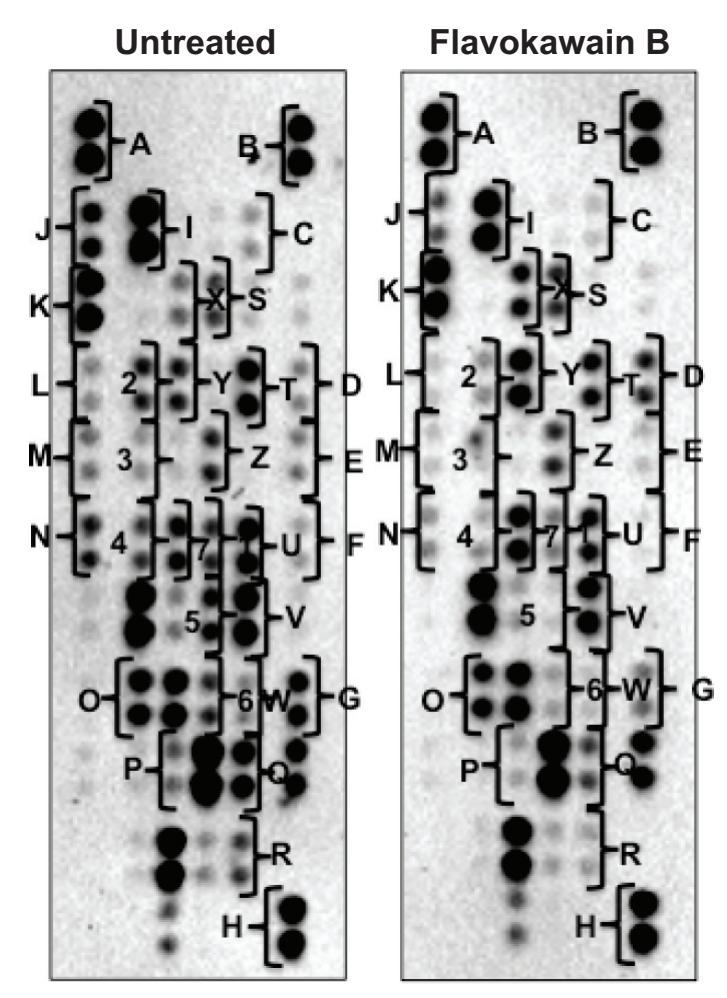

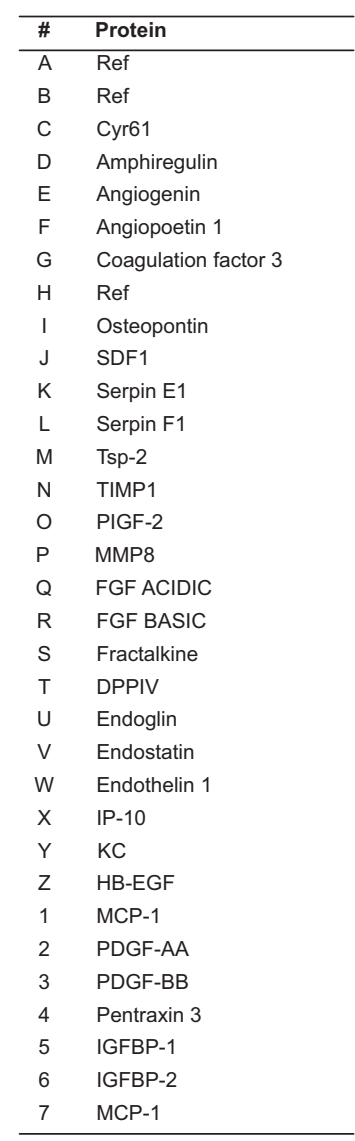

B

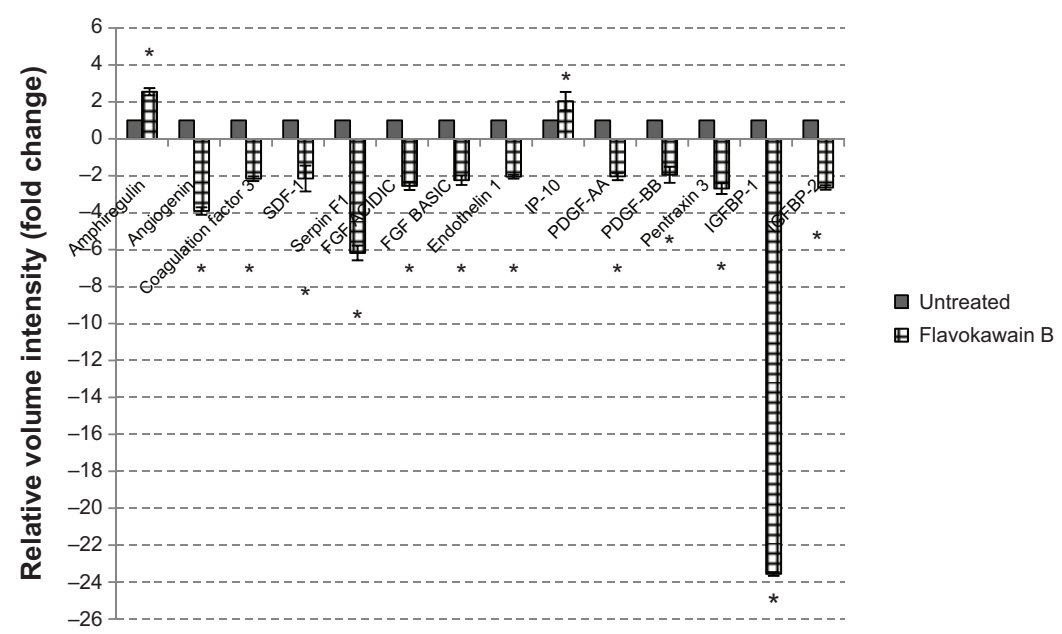

Figure 13 (A) Proteome profiler was performed to detect the changes in angiogenesis-related proteins on treatment with flavokawain B (50 mg/kg). (B) Proteins that are expressed with significant changes when treated with flavokawain $B(50 \mathrm{mg} / \mathrm{kg}) ; * P<0.05$.

tumors as a result of metastasis. Intercellular adhesion molecule 1 is also involved in the metastatic cascade. ${ }^{34,35}$

The reduction of pro-inflammatory mediators may render the cancer cells more susceptible to anticancer treatment. In addition, the anti-angiogenesis ability of FKB was further evaluated by detecting the regulation of several angiogenesisrelated proteins. The mechanism by which FKB conveys its antimetastatic ability is further widened, as it involved several different types of proteins. On the basis of the proteome profiler results, FKB significantly reduced the expression of angiogenin, coagulation factor 3, SDF-1, serpin F1, and TSP-2. Angiogenin is a ribonuclease that is known to be involved in the formation of new blood vessels, especially in embryonic, postnatal, and endometrium tissues. ${ }^{36}$ In fact, the level of 


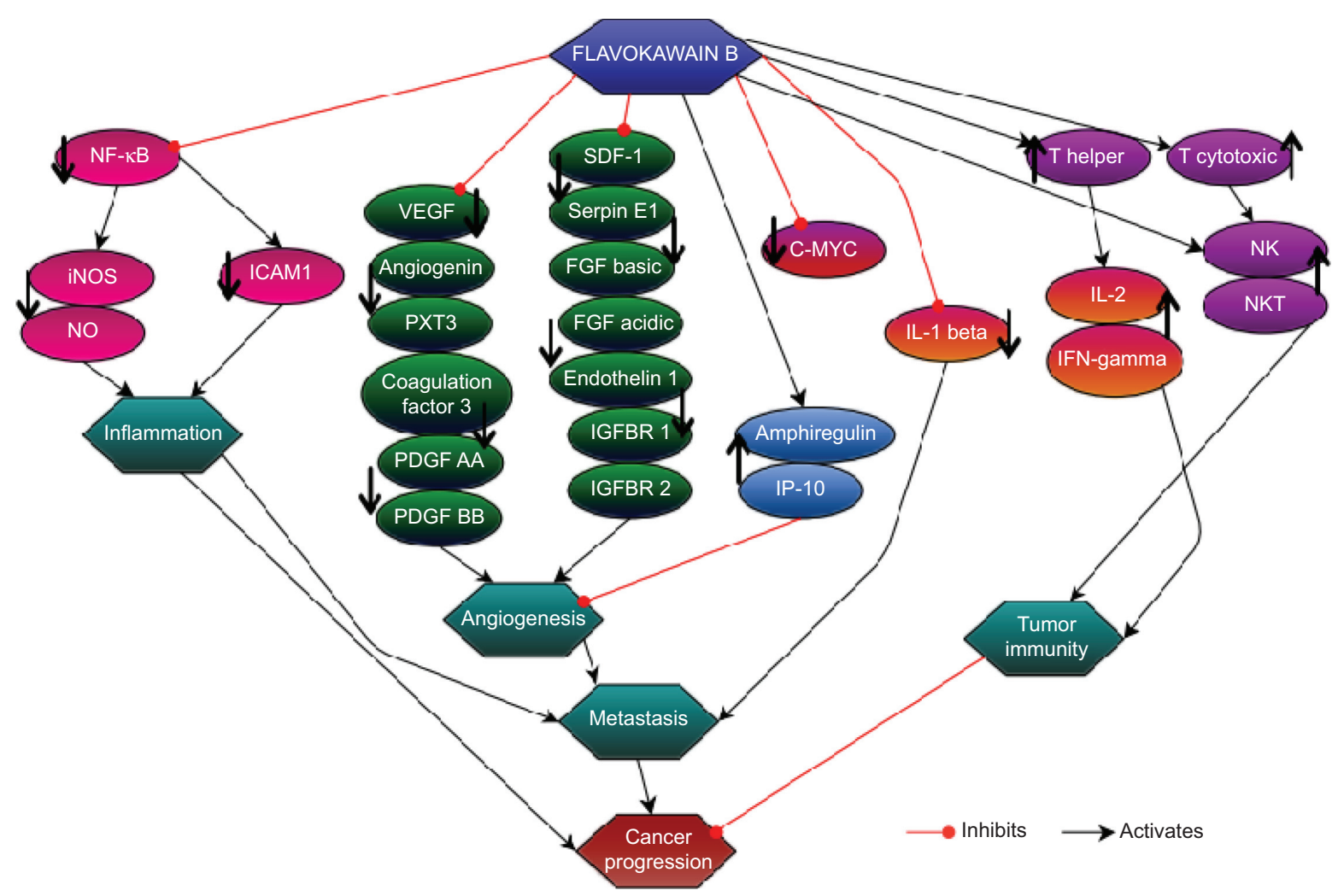

Figure 14 The direct and indirect effects of flavokawain B in regulating the immune system, metastasis, and inflammatory processes in relation to cancer progression.

angiogenin in the tissue may serve as a prognostic marker in primary breast carcinoma. ${ }^{37}$ Moreover, the expression of coagulation factor 3 was reduced significantly in FKB-treated tumors. Persistent expression of coagulation factor 3 can contribute to the development of cancer-related thrombosis. ${ }^{38}$ The interception of coagulation factor 3's activity may serve as a potential anti-angiogenic treatment, especially in breast cancer. ${ }^{38}$ Moreover, the level of SDF-1 was also reduced in the treated group. SDF-1 is often associated with CXCR4 in cancer pathogenesis. In breast cancer, the SDF-1/CXCR4 axis is reported to be important in the progression of angiogenesis. ${ }^{39}$ Serpin F1, otherwise known as pigment epithelium-derived factor, is also a potent inducer of angiogenesis and is reduced in the FKB-treated tumors. ${ }^{40}$ Furthermore, the levels of both FGF basic and acidic were reduced compared with levels in the control. Both FGF basic and acidic are more highly expressed in breast cancer tissues than normal tissues. ${ }^{41}$ Another growth factor, VEGF, is also significantly expressed in breast cancer tissues and is one of the main players in regulating angiogenesis. ${ }^{41}$ VEGF was also reduced in the FKB-treated tumors. The activation of VEGF can be initiated through the angiogenesis marker, endothelin $1 .{ }^{42}$

It has been put forward that the activation of IGFBR- 2 can also initiate the release of VEGF. ${ }^{43}$ In addition, PDGF-AA is also required to regulate the expression of VEGF. ${ }^{44} \mathrm{PDGF}-\mathrm{BB}$ is also known to contribute to angiogenesis. ${ }^{45}$ Another molecule worth noting is pentraxin 3 , which is found to have an upregulated expression in metastatic breast cancer and is also known to contribute to the poor survival rate of breast cancer patients. ${ }^{46}$ Therefore, an anticancer agent that can inhibit the expression of pentraxin 3 is favorable. IGFR1 antiangiogenic markers were also regulated by FKB. Amphiregulin is discovered to have antiangiogenic properties in tumors. ${ }^{47}$ This protein is upregulated in the tumors treated with FKB. Moreover, the level of IP-10 was also increased compared with the control group. IP-10 is known for its role in inhibiting VEGF-induced motility in the angiogenic process. ${ }^{48}$ Inhibition of inflammation and angiogenesis-related markers by FKB have further contributed to the reduction of the number of colonies formed in the lung, liver, and spleen. The distribution of cancer cells in secondary sites should be decreased, as these could contribute to the malignancy state of tumors. ${ }^{1,49}$ Cancer cells usually migrate to other sites, especially neighboring organs, through the blood or bone marrow. In the bone marrow smearing results, no abnormal or erratic cells were found in the FKB-treated mice, suggesting FKB could effectively inhibit the metastatic abilities of breast cancer cells to the spleen, liver, and bone marrow. 


\section{Conclusion}

On the basis of the results obtained from this study, FKB managed to halt the proliferation of 4T1 cells and the migration and invasiveness in vitro. This chalcone also reduced the size of the tumor and induced apoptosis in vivo. Moreover, FKB impeded the metastatic process in vivo as well as reduced the inflammatory process. Figure 14 depicts the possible direct and indirect mechanism of the activity of flavokawain in vivo, based on the results of this study. Nevertheless, more in-depth study should be conducted to fully understand the mechanism of FKB. Overall, FKB has a bright prospect of becoming an anticancer agent, and it should be further developed into the pharmaceutical line, especially for treating breast cancer.

\section{Acknowledgment}

We acknowledge Professor Tan Soon Guan for editing the English content of this manuscript.

\section{Disclosure}

The authors have no conflicts of interest in this work.

\section{References}

1. Siegel R, Naishadham D, Jemal A. Cancer statistics, 2013. CA Cancer J Clin. 2013;63(1):11-30.

2. Grivennikov SI, Greten FR, Karin M. Immunity, inflammation, and cancer. Cell. 2010;140(6):883-899.

3. Fv Z, Krupitza G, Mikulits W. Initial steps of metastasis: Cell invasion and endothelial transmigration. Mutat Res Rev Mutat Res. 2011; 728(1-2): 11 .

4. Batovska DI, Todorova IT. Trends in utilization of the pharmacological potential of chalcones. Curr Clin Pharmacol. 2010;5(1):1-29.

5. Lebot V, Merlin M, Lindstrom L. Kava: The Pacific Elixir: The Definitive Guide to Its Ethnobotany, History, and Chemistry. New Haven, CT: Yale University Press; 1997.

6. Dharmaratne HRW, Nanayakkara NPD, Khan IA. Kavalactones from Piper methysticum, and their 13C NMR spectroscopic analyses. Phytochemistry. 2002;59(4):429-433.

7. Abu N, Ho WY, Yeap SK, et al. The flavokawains: uprising medicinal chalcones. Cancer Cell Int. 2013;13(1):102.

8. Kuo YF, Su YZ, Tseng YH, Wang SY, Wang HM, Chueh PJ. Flavokawain B, a novel chalcone from Alpinia pricei Hayata with potent apoptotic activity: Involvement of ROS and GADD153 upstream of mitochondria-dependent apoptosis in HCT116 cells. Free Radic Biol Med. 2010;49(2):214-226.

9. Sakai T, Eskander RN, Guo Y, et al. Flavokawain B, a kava chalcone, induces apoptosis in synovial sarcoma cell lines. J Orthop Res. 2012; 30(7):1045-1050.

10. Tang Y, Li X, Liu Z, Simoneau AR, Xie J, Zi X. Flavokawain B, a kava chalcone, induces apoptosis via up-regulation of death-receptor 5 and Bim expression in androgen receptor negative, hormonal refractory prostate cancer cell lines and reduces tumor growth. Int J Cancer. 2010; 127(8):1758-1768.

11. Mohamad AS, Akhtar MN, Khalivulla SI, et al. Possible participation of nitric oxide/cyclic guanosine monophosphate/protein kinase C/ATPsensitive $\mathrm{K}(+)$ channels pathway in the systemic antinociception of flavokawin B. Basic Clin Pharmacol Toxicol. 2011;108(6):400-405.
12. Mosmann T. Rapid colorimetric assay for cellular growth and survival: application to proliferation and cytotoxicity assays. J Immunol Methods. 1983;65(1-2):55-63.

13. Liang CC, Park AY, Guan JL. In vitro scratch assay: a convenient and inexpensive method for analysis of cell migration in vitro. Nat Protoc. 2007;2(2):329-333.

14. Chen HC. Boyden chamber assay. Methods Mol Biol. 2005;294: $15-22$.

15. Zi X, Simoneau AR. Flavokawain A, a novel chalcone from kava extract, induces apoptosis in bladder cancer cells by involvement of Bax protein-dependent and mitochondria-dependent apoptotic pathway and suppresses tumor growth in mice. Cancer Res. 2005;65(8): 3479-3486.

16. DuPré SA, Redelman D, Hunter KW Jr. The mouse mammary carcinoma 4T1: characterization of the cellular landscape of primary tumours and metastatic tumour foci. Int J Exp Pathol. 2007;88(5):351-360.

17. Matassov D, Kagan T, Leblanc J, Sikorska M, Zakeri Z. Measurement of apoptosis by DNA fragmentation. Methods Mol Biol. 2004;282:1-17.

18. Weaver BAA, Cleveland DW. Decoding the links between mitosis, cancer, and chemotherapy: The mitotic checkpoint, adaptation, and cell death. Cancer Cell. 2005;8(1):7-12.

19. Liao DJ, Dickson RB. c-Myc in breast cancer. Endocr Relat Cancer. 2000;7(3):143-164.

20. Miller DM, Thomas SD, Islam A, Muench D, Sedoris K. c-Myc and cancer metabolism. Clin Cancer Res. 2012;18(20):5546-5553.

21. Gordan JD, Thompson CB, Simon MC. HIF and c-Myc: sibling rivals for control of cancer cell metabolism and proliferation. Cancer Cell. 2007; 12(2):108-113.

22. Xue M, Ge Y, Zhang J, et al. Fucoidan inhibited $4 \mathrm{~T} 1$ mouse breast cancer cell growth in vivo and in vitro via downregulation of Wnt/ $\beta$-catenin signaling. Nutr Cancer. 2013;65(3):460-468.

23. Xu D, Gu P, Pan PY, Li Q, Sato AI, Chen S-HNK. NK and CD8+ T cell-mediated eradication of poorly immunogenic B16-F10 melanoma by the combined action of IL-12 gene therapy and 4-1BB costimulation. Int $J$ Cancer. 2004;109(4):499-506.

24. Kershaw MH, Westwood JA, Darcy PK. Gene-engineered T cells for cancer therapy. Nat Rev Cancer. 2013;13(8):525-541.

25. Dranoff G. Cytokines in cancer pathogenesis and cancer therapy. Nat Rev Cancer. 2004;4(1):11-22.

26. Lai YP, Jeng CJ, Chen SC. The roles of $\mathrm{CD}^{+} \mathrm{T}$ cells in tumor immunity. ISRN Immunol. 2011;2011:1-6.

27. Kubota A, Lian RH, Lohwasser S, Salcedo M, Takei F. IFN- $\gamma$ production and cytotoxicity of IL-2-activated murine NK cells are differentially regulated by MHC class I molecules. J Immunol. 1999;163(12): 6488-6493.

28. Zaidi MR, Merlino G. The two faces of interferon- $\gamma$ in cancer. Clin Cancer Res. 2011;17(19):6118-6124.

29. Voronov E, Shouval DS, Krelin Y, et al. IL-1 is required for tumor invasiveness and angiogenesis. Proc Natl Acad Sci USA. 2003;100(5): $2645-2650$

30. Wu Y, Zhou BP. Inflammation: a driving force speeds cancer metastasis. Cell Cycle. 2009;8(20):3267-3273.

31. Hickok JR, Thomas DD. Nitric oxide and cancer therapy: the emperor has NO clothes. Curr Pharm Des. 2010;16(4):381-391.

32. Sharma JN, Al-Omran A, Parvathy SS. Role of nitric oxide in inflammatory diseases. Inflammopharmacology. 2007;15(6):252-259.

33. Frank PG, Lisanti MP. ICAM-1: role in inflammation and in the regulation of vascular permeability. Am J Physiol Heart Circ Physiol. 2008; 295(3):H926-H927.

34. Rosette C, Roth RB, Oeth P, et al. Role of ICAM1 in invasion of human breast cancer cells. Carcinogenesis. 2005;26(5):943-950.

35. Singh B, Berry JA, Shoher A, Ayers GD, Wei C, Lucci A. COX-2 involvement in breast cancer metastasis to bone. Oncogene. 2007; 26(26): 3789-3796.

36. Shestenko OP, Nikonov SD, Mertvetsov NP. Angiogenin and its functions in angiogenesis. Mol Biol. 2001;35(3):20. 
37. Montero S, Guzmán C, Cortés-Funes H, Colomer R. Angiogenin expression and prognosis in primary breast carcinoma. Clin Cancer Res. 1998;4(9):2161-2168.

38. Ruf W, Yokota N, Schaffner F. Tissue factor in cancer progression and angiogenesis. Thromb Res. 2010;125(2)(suppl 2):S36-S38.

39. Jin F, Brockmeier U, Otterbach F, Metzen E. New insight into the SDF-1/CXCR4 axis in a breast carcinoma model: hypoxia-induced endothelial SDF-1 and tumor cell CXCR4 are required for tumor cell intravasation. Mol Cancer Res. 2012;10(8):1021-1031.

40. Ek, ETH Dass CR, Choong PFM. PEDF: a potential molecular therapeutic target with multiple anti-cancer activities. Trends Mol Med. 2006; 12(10):5

41. Reif M, Lejeune S, Scott PAE, et al. Expression of the Angiogemc Factors Vascular Endothelial Cell Growth Factor, Acidic and Basic Fibroblast Growth Factor, Tumor Growth Factor @3-1,Plateletderived Endothelial Cell Growth Factor, Placenta Growth Factor, and Pleiotrophin in Human Primary Breast Cancer and Its Relation to Angiogenesis. Cancer Res. 1997;57:8.

42. Bagnato A, Spinella F. Emerging role of endothelin-1 in tumor angiogenesis. Trends Endocrinol Metab. 2003;14(1):44-50.
43. Das SK, Bhutia SK, Azab B, et al. MDA-9/syntenin and IGFBP-2 promote angiogenesis in human melanoma. Cancer Res. 2013;73(2):844-854.

44. Shikada Y, Yonemitsu Y, Koga T, et al. Platelet-derived growth factor-AA is an essential and autocrine regulator of vascular endothelial growth factor expression in non-small cell lung carcinomas. Cancer Res. 2005;65(16):7241-7248.

45. Battegay EJ, Rupp J, Iruela-Arispe L, Sage EH, Pech M. PDGF-BB modulates endothelial proliferation and angiogenesis in vitro via PDGF beta-receptors. J Cell Biol. 1994;125(4):917-928.

46. Choi B, Lee EJ, Song DH, et al. Elevated Pentraxin 3 in bone metastatic breast cancer is correlated with osteolytic function. Oncotarget. 2014;5(2):481-492.

47. Ma L, Gauvillé C, Berthois Y, Millot G, Johnson GR, Calvo F. Antisense expression for amphiregulin suppresses tumorigenicity of a transformed human breast epithelial cell line. Oncogene. 1999;18(47):6513-6520.

48. Bodnar RJ, Yates CC, Wells A. IP-10 blocks vascular endothelial growth factor-induced endothelial cell motility and tube formation via inhibition of calpain. Circ Res. 2006;98(5):617-625.

49. Lu J, Steeg PS, Price JE, et al. Breast cancer metastasis: challenges and opportunities. Cancer Res. 2009;69(12):4951-4953.

\section{Publish your work in this journal}

Drug Design, Development and Therapy is an international, peerreviewed open-access journal that spans the spectrum of drug design and development through to clinical applications. Clinical outcomes, patient safety, and programs for the development and effective, safe, and sustained use of medicines are a feature of the journal, which

\section{Dovepress}

has also been accepted for indexing on PubMed Central. The manuscript management system is completely online and includes a very quick and fair peer-review system, which is all easy to use. Visit http://www.dovepress.com/testimonials.php to read real quotes from published authors.

Submit your manuscript here: http://www.dovepress.com/drug-design-development-and-therapy-journal 